\title{
Hepatocyte nuclear factor $4 \alpha$ transactivates the mitochondrial alanine aminotransferase gene in kidney of Sparus aurata
}

\author{
María C. Salgado ${ }^{a}$, Isidoro Metón ${ }^{a}$, Ida G. Anemaet ${ }^{a}$, J. Diego González ${ }^{a}$, Felipe \\ Fernández $^{\mathrm{b}}$ and Isabel V. Baanante ${ }^{\mathrm{a}^{*}}$
}

${ }^{a}$ Departament de Bioquímica i Biologia Molecular, Facultat de Farmàcia, Universitat de Barcelona, Joan XXIII s/n, 08028 Barcelona, Spain

\footnotetext{
'Departament d'Ecologia, Facultat de Biologia, Universitat de Barcelona, Diagonal 645, 08028 Barcelona, Spain
}

Running title: Transactivation of Sparus aurata mALT by HNF4 $\alpha$

Keywords: hepatocyte nuclear factor $4 \alpha$, kidney, mitochondrial alanine aminotransferase, Sparus aurata, starvation, streptozotocin.

\footnotetext{
* Corresponding author and to whom reprint requests should be addressed: Isabel V. Baanante, Departament de Bioquímica i Biologia Molecular, Facultat de Farmàcia, Universitat de Barcelona, Joan XXIII s/n, 08028 Barcelona, Spain. Tel.: +34 934024521; Fax: +34 934024520; E-mail: baanantevazquez@ub.edu
} 


\begin{abstract}
Alanine aminotransferase (ALT) plays an important role in amino acid metabolism and gluconeogenesis. The preference of carnivorous fish for protein amino acids instead of carbohydrates as a source of energy lead us to study the transcriptional regulation of the mitochondrial ALT (mALT) gene and to characterize the enzyme kinetics and modulation of mALT expression in kidney of gilthead sea bream (Sparus aurata) under different nutritional and hormonal conditions. 5'-deletion analysis of mALT promoter in transiently transfected HEK293 cells, site-directed mutagenesis and electrophoretic mobility shift assays allowed us to identify HNF4 $\alpha$ as a new factor involved in the transcriptional regulation of mALT expression. Quantitative RT-PCR assays showed that starvation and the administration of streptozotocin (STZ) decreased HNF4 $\alpha$ levels in the kidney of $S$. aurata, leading to down-regulation of mALT transcription. Analysis of the tissue distribution showed that kidney, liver and intestine were the tissues with higher mALT and HNF4 $\alpha$ expression. Kinetic analysis indicates that mALT enzyme is more efficient in catalyzing the conversion of L-alanine to pyruvate than the reverse reaction. From these results we conclude that HNF4 $\alpha$ transactivates the mALT promoter and that the low levels of mALT expression found in the kidney of starved and STZ-treated fish result from a decreased expression of HNF4 $\alpha$. Our findings suggest that the mALT isoenzyme plays a major role in oxidazing dietary amino acids, and points to ALT as a target for a biotechnological action to spare protein and optimize the use of dietary nutrients for fish culture.
\end{abstract}




\section{Introduction}

Carnivorous fish have little capacity to utilize dietary carbohydrates, instead they efficiently use the protein amino acids for growth and to obtain energy. In fact, amino acids appear to be a more important energy source than carbohydrates in these animals. The limited capacity to metabolize dietary carbohydrates and a metabolic profile that mimics non-insulin-dependent diabetes mellitus in mammals after a glucose load, led to consider these animals as glucose intolerant (Cowey and Walton, 1989; Moon, 2001; Hemre et al., 2002).

Alanine aminotransferase (ALT; EC 2.6.1.2) links carbohydrate and amino acid metabolism through catalysing the reversible transamination between L-alanine and 2oxoglutarate to form pyruvate and L-glutamate. The presence of ALT isoforms in the cytosol and mitochondria has been proposed on the basis of biochemical studies (De Rosa and Swick, 1975). In humans and mice, two ALT isoforms, ALT1 and ALT2, each encoded by a different gene, have been cloned (Sohocki et al., 1997; Yang et al., 2002; Jadhao et al., 2004). In fish, levels of ALT activity in the liver are used as an indicator of protein utilization (Fynn-Aikins et al., 1995; Sánchez-Muros et al., 1998; Metón et al., 1999; Fernández et al., 2007). We reported the presence of three ALT isoforms in Sparus aurata. The two first cloned isoforms were the cytosolic cALT1 and the first reported animal amino acid sequence for a mitochondrial ALT, mALT (Metón et al., 2004). Recent studies indicated that alternative splicing of $S$. aurata cytosolic ALT gene generates a second cALT isoform, cALT2. In fish liver, expression of cALT2 is associated with enhanced gluconeogenesis, while cALT1 is predominant during postprandial utilization of dietary nutrients (Anemaet et al., 2008). 
Knowledge of the transcriptional control of ALT genes is scarce. Gray et al. (2007) showed that the transcription factor Krüppel-like factor 15, induces expression of the ALT1 gene; however, direct transactivation of the promoter remains to be determined. Peroxisome proliferator-activated receptor $\alpha$ has recently been shown to activate the human ALT1 promoter, but not ALT2 promoter activity (Thulin et al., 2008). More recently, Anemaet et al. (2010), showed that the transcription factors p300 and cMyb transactivate the cALT promoter and that p300 could be involved in the upregulation of cALT2 expression observed in streptozotocin (STZ)-treated fishes.

Hepatocyte Nuclear Factor 4 alpha $(\mathrm{HNF} 4 \alpha)$ is a member of the Nuclear Receptor Superfamily (NRS) and binds to DNA as a homodimer (Sladek et al., 1990). The HNF4 $\alpha$ protein contains a constitutive autonomous activator of transcription (activation function-1, AF-1), two zinc finger motifs that specifically bind to DR1 elements found in promoters of target genes (DNA binding domain, DBD), a ligand binding domain (LBD) responsible for dimerization, a hydrophobic AF-2 transactivation domain, and a negative regulatory activity domain (HadzopoulouCladaras et al., 1997; Jiang and Sladek, 1997; Duda et al., 2004). In humans, at least nine HNF4 $\alpha$ isoforms have been cloned and characterized (Sladek and Seidel, 2001). These isoforms result from both alternative splicing and alternative usage of promoters P1 and P2 (Eeckhoute et al., 2003a). In vertebrates, HNF4a is mainly expressed in the liver, intestine, kidney and pancreas (Sladek and Seidel, 2001).

HNF4 $\alpha$ plays a critical role in the transcriptional regulation of genes involved in different processes, such as carbohydrate, amino acid and lipid metabolism, among others (Stoffel and Duncan, 1997; Hayhurst et al., 2001; Sladek and Seidel, 2001; Kardassis, 2002; Schrem et al., 2002; Salgado et al., 2004). In various experiments with HNF4 $\alpha$ deficient mice, HNF4 $\alpha$ has been shown to establish the liver phenotype (Li et 
al., 2000; Hayhurst et al., 2001; Inoue et al., 2002; Parviz et al., 2003), regulate epithelial differentiation in the colon (Garrison et al., 2006) and control insulin secretion (Gupta et al., 2005; Miura et al., 2006), as well as to respond to increased metabolic demand in pancreatic $\beta$-cells (Gupta et al., 2007). In contrast, the physiological role of HNF4 $\alpha$ in other organs, especially in the kidney, remains largely unknown.

Molecular studies devoted to unravel the bases that govern regulation of ALT gene expression in carnivorous fish are scarce. The aim of this study is to increase the current knowledge of fish intermediary metabolism to allow future biotechnological actions to improve metabolic utilization of dietary nutrients. In the present study we characterized for the first time the mALT promoter and addressed the role of HNF4 $\alpha$ in the transcriptional control of mALT in kidney of $S$. aurata, one of the most extensively culture marine fish in the Mediterranean. We determined the kinetics of the mALT enzyme and studied the regulation of the expression of HNF4 $\alpha$ and mALT in kidney after starvation and in insulin- and STZ-treated S. aurata.

\section{Material and methods}

\section{Experimental animals}

Gilthead sea bream (S. aurata) obtained from Tinamenor (Cantabria, Spain) were maintained, at $20^{\circ} \mathrm{C}$, in 260 -L aquaria as previously described (Fernández et al., 2007). The diet supplied to the animals contained $46 \%$ protein, $9.3 \%$ carbohydrates, $22 \%$ lipids, $10.6 \%$ ash, $12.1 \%$ moisture and $21.1 \mathrm{~kJ} / \mathrm{g}$ gross energy. Unless stated otherwise, fish were fed $25 \mathrm{~g} / \mathrm{kg}$ body weight (BW) once a day (10 a.m.). The effect of starvation on the expression of mALT and HNF4 $\alpha$ was analyzed in the kidney of fish deprived of 
food for 19 days and in fed fish. To study regulation of mALT and HNF4 $\alpha$ expression by insulin and STZ, the animals were divided into three groups. Thirty $\mathrm{h}$ before sampling, two groups of fish received an intraperitoneal injection with saline and another group was intraperitoneally injected with STZ (600 mg/Kg fish; Sigma-Aldrich, St. Louis, MO, USA). Six h before sampling, one group of fish previously treated with saline received an intraperitoneal dosis of bovine insulin (10 units/Kg fish; SigmaAldrich, St. Louis, MO, USA). To prevent stress, fish were anesthetized with MS-222 $(1: 12,500)$ before handling (9:30 a.m.). After fish were killed by cervical section, blood was collected and tissue samples were dissected out, immediately frozen in liquid $\mathrm{N}_{2}$, and kept at $-80{ }^{\circ} \mathrm{C}$ until use. The experimental procedures complied with the guidelines of the Animal Use Committee of the Universitat de Barcelona.

Cloning of the 5 '-flanking region of $m A L T$ gene from $S$. aurata

The 5'-flanking region of mALT was isolated by PCR with the Universal Genome Walker Kit (Clontech). Four libraries obtained by blunt-end digestion of S. aurata genomic DNA with DraI, EcoRV, PvuII and StuI are ligated to the GenomeWalker adaptor from the kit as previously described elsewhere (Metón et al., 2006). Primary PCR was performed on each library using the gene-specific primer MC01 and the AP-1 primer provided in the kit. Nested PCR was performed on the primary PCR product with the gene-specific primer MC02 and the AP2 primer from the kit. The longest amplification product, a single 912 bp band, obtained with the StuI library was ligated into pGEM-T Easy plasmid (Promega) to generate pGEM-mALT820. A second round of chromosome walking was performed using gene-specific primers MC03 and MC04 for the primary and nested PCR, respectively. The $846 \mathrm{bp}$ fragment obtained from the 
DraI library was ligated into the pGEM-T Easy plasmid (Promega) to generate pGEMmALT846. Two independent clones were fully sequenced on both strands according to the ABI Prism BigDye Terminator Cycle Sequencing Ready Reaction Kit instructions (Applied Biosystems, Foster City, CA, USA).

Construction of reporter gene plasmids

The $S$. aurata mALT-luciferase reporter fusion construct, which harbours promoter sequences located between positions -820 and +92 relative to the transcription start site (pGmALT820) was generated by PCR. To this end, the gene-specific primers MC05 and MC06 were used together with pGEM-mALT820 as a template. The PCR product was restricted with MluI/HindIII and ligated into the pGL3-Basic promoterless luciferase reporter plasmid (Promega) previously digested with MluI/HindIII. To obtain the pGmALT1540 reporter construct $(-1540$ to $+92 \mathrm{bp})$, the MluI/Pst $\mathrm{I}$ fragment $(-1540$ to -519) from pGEM-mALT846 was cloned into the pGmALT820 plasmid previously digested by the same restriction enzymes. Reporter constructs pGmALT519 (-519 to $+92 \mathrm{bp})$ and pGmALT $+62(+62$ to $+92 \mathrm{bp})$ were obtained by self-ligation of filled-in ends of pGmALT820 after digestion with PmacI/MluI and BstI/MluI, respectively. The construct pGmALT325 (-325 to $+92 \mathrm{bp}$ ) was obtained by digesting pGmALT820 with $B s t$ EII/MluI followed by chew-back and filled-in reactions with Klenow enzyme and self-ligation. The pGmALT103 (-103 to +92 bp) and pGmALT49 (-49 to +92 bp) plasmids were obtained by PCR using primer pairs MC07/MC05 and MC08/MC05 respectively, and pGmALT820 as a template. Construct pGmALT1540 $103-49$ (-1540 to +92 bp relative to the transcription start site, and including the deletion of nucleotides -103 to -49 ) was obtained by PCR using MC09 and MC05 as primers. The PCR product 
was digested with PmacI and HindIII and ligated to the pGmALT1540 construct, previously digested with the same enzymes. Construct pGmALT1540mutHNF4 (-1540 to $+92 \mathrm{bp}$ ), which harbours a mutated HNF4 $\alpha$ binding site, was obtained by PCR using oligonucleotides MC10 and MC05. The PCR product was digested with Esp3I and HindIII and ligated to the pGmALT1540 construct, previously digested with the same enzymes. All constructs were verified by cycle sequencing.

Molecular cloning of $H N F 4 \alpha$ cDNA from $S$. aurata

RT-PCR experiments were carried out with total RNA from S. aurata tissues. The synthesized cDNA was used as a template for PCR using primers MC19 and MC20, designed from data bank sequences for HNF4a. The PCR was conducted through 35 cycles of denaturation at $94^{\circ} \mathrm{C}$ for $30 \mathrm{sec}$, annealing at $55^{\circ} \mathrm{C}$ for $40 \mathrm{sec}$ and DNA synthesis at $72^{\circ} \mathrm{C}$ for $2 \mathrm{~min}$, followed by a final extension step of $5 \mathrm{~min}$. A single 1080 bp band was isolated and ligated into pGEM T easy (Promega). Sequence analysis of the resulting construct was thereafter used to design oligonucleotides to perform RACE experiments with the SMART ${ }^{\mathrm{TM}}$ RACE cDNA Amplification Kit (Clontech).

To conduct the 5'-RACE experiments, a cDNA strand was synthesized, using Sparus aurata total RNA, the 5'-CDS primer and the SMART II A oligonucleotide (provided in the kit). A primary PCR was performed with MC23 and the Universal Primer Mix A (UPM) provided in the kit. A secondary touchdown PCR assay was carried out on the primary PCR product using the nested MC24 and the Nested Universal Primer Mix A (NUPM) from the kit. A second round of 5'-RACE was performed using MC25 and UPM for the primary PCR and MC26 and NUPM as primers for nested PCR. 
3'-RACE was performed on cDNA generated from $S$. aurata total RNA and the 3'-CDS primer. An initial PCR round was performed using MC27 and UPM primer pair. A secondary touchdown PCR was carried out on the primary PCR product using the nested MC28 and the anchor primer from the kit. DNA fragments generated by RACE PCR were ligated into pGEM T easy plasmid (Promega). Two independent clones were fully sequenced on both strands in each case.

The full-coding sequence of $S$. aurata kidney HNF4 $\alpha$ was amplified by RT-PCR using MC21 and MC22 as primers. The resulting product was restricted with BamHI and HindIII and ligated into pcDNA3, previously digested with the same enzymes, to generate pcDNA3-saHNF4 $\alpha$. Two independent clones were fully sequenced on both strands.

\section{Cell transfection and luciferase assay}

The human embryonic kidney cell line HEK293 (ATCC, CRL-1573) was cultured in Dulbecco's modified Eagle's medium (DMEM), supplemented with $10 \%$ fetal bovine serum, $100 \mathrm{IU} / 1$ penicillin, $100 \mu \mathrm{g} / \mathrm{ml}$ streptomycin, $2 \mathrm{mM}$ glutamine and $110 \mathrm{mg} / \mathrm{L}$ sodium pyruvate. The cells were grown in six-well plates at $37^{\circ} \mathrm{C}$ in $5 \% \mathrm{CO}_{2}$. The calcium phosphate coprecipitation method was used for the transient transfection of HEK293 cells at 45-55\% confluence. Cells were transfected with $2 \mu \mathrm{g}$ of reporter construct, and when necessary, with $200 \mathrm{ng}$ of expression vector encoding rat or $S$. aurata HNF4 $\alpha$. To correct for variations in transfection efficiency, $250 \mathrm{ng}$ of CMV- $\beta$ (lacZ) plasmid were included in each transfection.

The cells were harvested $16 \mathrm{~h}$ later, washed in phosphate-buffered saline (PBS) and incubated for 15 min with $300 \mu$ of Cell Culture Lysis Reagent (Promega). Cell 
debris was removed by centrifugation at $10000 \mathrm{~g}$ for $30 \mathrm{sec}$, and luciferase activity was measured in the supernatant after the addition of the Luciferase Assay Reagent (Promega) in a TD-20/20 Luminometer (Turner Designs). The activity of $\beta$ galactosidase in $20-50 \mu 1$ of the clear lysate was measured as previously described (Metón et al., 2006). The expression plasmid encoding rat HNF4 $\alpha$ (pcDNA3.HNF4 $\alpha$; (Bartoov-Shifman et al., 2002), was kindly provided by Dr. M. D. Walker (Weizmann Institute of Science, Israel).

Nuclear extracts

Nuclear extracts were prepared from $S$. aurata as described by Andrews and Faller (1991) with minor modifications, all the steps were performed at $4^{\circ} \mathrm{C}$. One hundred $\mathrm{mg}$ of frozen liver were homogenized in $400 \mu 1$ of cold PBS. The cells were pelleted by centrifugation for $10 \mathrm{sec}$ at $1000 \mathrm{x} \mathrm{g}$, washed twice in $400 \mu \mathrm{l}$ of cold PBS, and resuspended in $400 \mu$ of buffer A [10 mM HEPES-KOH (pH 7.9), $1.5 \mathrm{mM} \mathrm{MgCl} 2,10$ $\mathrm{mM} \mathrm{KCl}, 0.5 \mathrm{mM}$ dithiothreitol (DTT), and $0.2 \mathrm{mM}$ phenylmethylsulfonyl fluoride (PMSF)]. After $10 \mathrm{~min}$ incubation, cells were vortexed for $10 \mathrm{sec}$. Samples were pelleted and resuspended in $20 \mu 1$ of cold buffer C (20 mM HEPES-KOH (pH 7.9), 25\% glycerol, $420 \mathrm{mM} \mathrm{NaCl}, 1.5 \mathrm{mM} \mathrm{MgCl}_{2}, 0.2 \mathrm{mM}$ EDTA, $0.5 \mathrm{M}$ DTT, and $0.2 \mathrm{mM}$ PMSF), and then incubated 20 min for high-salt extraction. After removing cellular debris, the supernatant fraction was aliquoted and stored at $-80^{\circ} \mathrm{C}$.

Electrophoretic mobility shift assay 
One hundred pmols of double-stranded oligonucleotides (HNF4 $\alpha$-cons, mALT-66/-37 and mALT-66/-37mutHNF4) were 3'-end labeled with digoxigenin-11-ddUTP using terminal transferase (Roche) for $30 \mathrm{~min}$, at $37^{\circ} \mathrm{C}$. Binding reactions were carried out in a total volume of $20 \mu \mathrm{l}$ containing: $100 \mathrm{mM}$ Hepes, $\mathrm{pH}$ 7.6, $5 \mathrm{mM}$ EDTA, $50 \mathrm{mM}$ $\left(\mathrm{NH}_{4}\right)_{2} \mathrm{SO}_{4}, 5 \mathrm{mM}$ DTT, $1 \%$ Tween $20,150 \mathrm{mM} \mathrm{KCl}, 1 \mu \mathrm{g}$ of non-specific competitor poly [d(I-C)] (Roche), S. aurata nuclear extracts, and the labeled probe. The DNAprotein complexes were electrophoresed, at $4^{\circ} \mathrm{C}$, on $5 \%$ polyacrylamide gel using $0.5 \mathrm{X}$ TBE as buffer. Thereafter, DNA was transferred by contact blotting $(2 \mathrm{~h}$ at room temperature) to Nytran membranes (Schleicher \& Schuell), and cross-linked to membranes by UV irradiation for 3 min. Labeled probes were immuno-detected with anti-digoxigenin conjugated to alkaline phosphatase (Roche) and with CDP-Star ${ }^{\mathrm{TM}}$ (Roche) as chemiluminiscent substrate. Membranes were finally exposed to Hyperfilm $^{\mathrm{TM}}$ ECL (Amersham). For competition experiments, liver S. aurata nuclear extracts were preincubated for 30 min with a 10- to 100-fold molar excess of unlabeled double-stranded HNF4 $\alpha$-cons oligonucleotide. For supershift assays, $20 \mu \mathrm{g}$ of HNF4 $\alpha$ antibody (sc-8987 X, Santa Cruz Biotechnology) were incubated with nuclear proteins from $S$. aurata extracts, for $30 \mathrm{~min}$ at room temperature, before addition of the probe to the binding reaction mixture.

\section{Quantitative real time PCR}

The reverse transcriptase reaction was performed on $5 \mu \mathrm{g}$ total RNA isolated from kidney tissue of S. aurata by incubation with Moloney Murine Leukemia Virus (MMLV) RT (Invitrogen) for $60 \mathrm{~min}$ at $37^{\circ} \mathrm{C}$ in the presence of random hexamer primers. 
The cDNA product was used for subsequent quantitative real time PCR (qRT-PCR) analysis.

HNF4 $\alpha$ and mALT mRNA levels were determined in an ABI Prism 7000 Sequence Detection System (Applied Biosystems) using $0.4 \mu \mathrm{M}$ of each primer (MC15/MC16 and JDRTm1S/JDRTm1AS for HNF4 $\alpha$ and ALTm respectively), $10 \mu 1$ of SYBR Green (Applied biosystems) and $1.6 \mu 1$ of the diluted cDNA mixture in a final volume of $20 \mu \mathrm{l}$. The amount of mRNA to be used for the gene of interest in each of the samples was normalized with $S$. aurata ribosomal-18s using the primers JDRT18S and JDRT18AS (Table 1). Variations in gene expression were calculated by the standard $\Delta \Delta \mathrm{Ct}$ method. Each experiment was performed at least three times.

Yeast growth and transformation

S. cerevisiae putative mitochondrial ALT deletion strain YLR089c (Euroscarf, Frankfurt, Germany; genotype BY4743; MAT a/ $\alpha$, his $3 \Delta 1 /$ his $3 \Delta 1$; leu2 $\Delta 0 / 1$ eu2 $\Delta 0$; lys $2 \Delta 0 /$ LYS2; $\quad$ MET $15 / \operatorname{met} 15 \Delta 0 ; \quad \operatorname{ura} 3 \Delta 0 /$ ura $3 \Delta 0$ YLR089c::kanMX4/YLR089c::kanMX4) was transformed using the lithium acetate procedure (Schiestl and Gietz, 1989). Transformed yeasts were grown in complete minimal medium $\left(5 \mathrm{~g} / \mathrm{L}\left(\mathrm{NH}_{4}\right)_{2} \mathrm{SO}_{4}, 1.7 \mathrm{~g} / \mathrm{L}\right.$ yeast nitrogen base and $0.77 \mathrm{~g} / \mathrm{L}$ yeast dropout powder) lacking uracil ( $\left.\mathrm{CMUra}^{-}\right)$with $2 \%$ glucose as carbon source until $\mathrm{OD}_{600}=1$. Thereafter, the mitochondria were induced by adding $\mathrm{CMUra}^{-}$supplemented with $2 \%$ lactic acid so that $\mathrm{OD}_{600}=0,1$ and then it was incubated at $30^{\circ} \mathrm{C}$ since $\mathrm{OD}_{600}=1$. Finally, GAL1-promoter activity of pYmALT was induced by adding a $2 \%$ galactose to the culture and let it grow $20 \mathrm{~h}$ more at $30{ }^{\circ} \mathrm{C}$. To recover protein extracts, cells were sedimented at $3000 \mathrm{~g}$ for $5 \mathrm{~min}$ at $4{ }^{\circ} \mathrm{C}$, washed twice and resuspended in mitochondria 
isolation buffer (MIB) containing $210 \mathrm{mM}$ manitol, $70 \mathrm{mM}$ sucrose, $5 \mathrm{mM}$ HEPES$\mathrm{KOH} \mathrm{pH} 7.35,1 \mathrm{mM}$ EDTA and a protease inhibitor cocktail for yeast (SigmaAldrich). After addition of one volume of cold acid-washed glass beads (SigmaAldrich) the cells were disrupted by vigorous vortexing and homogenates were centrifuged at $800 \mathrm{~g}$ for $5 \mathrm{~min}$ at $4{ }^{\circ} \mathrm{C}$. The resulting supernatants were centrifuged at $10,000 \mathrm{~g}$ for $15 \mathrm{~min}$ at $4{ }^{\circ} \mathrm{C}$. The pellet was washed twice in MIB and then resuspended in lysis buffer containing Tris- $\mathrm{HCl} 50 \mathrm{mM}$ pH 7.5 and protease inhibitor cocktail for yeast (Sigma-Aldrich). The mitochondrial fraction after desalted through a Sephadex G-25 column was immediately frozen with a $10 \%$ glicerol and stored at $-40{ }^{\circ} \mathrm{C}$.

pYmALT construct was generated by PCR using primer pairs YH1/IMAL24 (Table 1), and pGEMmALT as template. The PCR product was digested with BamHI and HindIII and ligated into the GAL-inducible pYES2 vector (Invitrogen, Paisley, UK), previously digested with the same enzymes. The construct was verified by sequencing.

Enzyme activity assays

The reaction in the direction of L-glutamate formation (forward reaction) was measured at $30{ }^{\circ} \mathrm{C}$ in a Cobas Mira S spectrophotometric analyser (Hoffman-La Roche, Basel, Switzerland) by monitoring oxidation of NADH at $340 \mathrm{~nm}$ in a mix containing $0.1 \mathrm{M}$ phosphate buffer $\mathrm{pH}$ 7.12, L-alanine and 2-oxoglutarate at different concentrations, 0.18 $\mathrm{mM} \mathrm{NADH}, 1.4 \mathrm{U} / \mathrm{mL}$ lactate dehydrogenase, and desalted yeast protein extract. In order to study the reaction in the direction of alanine formation (reverse reaction), a two step assay was performed: pyruvate and glutamate at various concentrations were incubated in $0,1 \mathrm{M}$ Tris-HCl buffer $\mathrm{pH} 7,82$ at $30^{\circ} \mathrm{C}$ for 3 minutes with the desalted 
yeast protein extract. After inactivation of the enzyme with trichloroacetic acid and later neutralization of the mixture by adding $\mathrm{NaOH} 3 \mathrm{M}$, the 2-oxoglutarate formed was measured by oxidation of $\mathrm{NADH}$ at $30{ }^{\circ} \mathrm{C}$ in a Cobas Mira $\mathrm{S}$ spectrophotometric analyser in the presence of $0.1 \mathrm{M}$ Tris- $\mathrm{HCl} \mathrm{pH} 7.8,0.18 \mathrm{mM}, \mathrm{NADH}, 10.04 \mathrm{U} / \mathrm{mL}$ glutamate dehydrogenase and $33 \mathrm{mM}$ ammonium sulfate.

For both forward and reverse reactions, measured in conditions of maximal activity, a unit of enzyme activity was defined as the amount of enzyme consuming 1 $\mu$ mol of NADH per min. Protein content in yeast extracts was determined by the Bradford method at $30{ }^{\circ} \mathrm{C}$ using bovine serum albumin as a standard (Bradford, 1976). Fifteen $\mu \mathrm{g}$ of mitochondrial protein were used for the kinetic assays.

Lineweaver-Burk (double-reciprocal) plots were used to calculate the kinetic parameters of two independent enzyme preparations. The optimum $\mathrm{pH}$ value for the enzyme activity was determined at various $\mathrm{pH}$ values between 4.0 and 9.3 in protein extracts from yeast expressing mALT.

Western blot analysis

Fifty micrograms of mitochondrial protein was loaded per lane of a $10 \%$ polyacrylamide gel and electrophoresed in the presence of sodium dodecyl sulfate. After electrophoresis the gel was equilibrated in transfer buffer $(25 \mathrm{mM}$ Tris, $192 \mathrm{mM}$ glycine, 20\% methanol, $\mathrm{pH} 8.3$ ) and electroeluted onto NytranN nylon membranes (Whatman, Kent, UK) for $3 \mathrm{~h}$ at $60 \mathrm{~V}$ and $4{ }^{\circ} \mathrm{C}$. Following the Immun-Star ${ }^{\mathrm{TM}}$ Substrate Kit (Bio-Rad, Hercules, CA, USA) procedure, a rabbit polyclonal antibody raised against a common domain of S.aurata ALT isozymes was used as primary antibody $(1: 1000)$ to detect mALT expression in transformed yeast. 


\section{Statistics}

Data were analysed by one-factor analysis of variance using a computer program (StatView, Cary, NC, USA). Differences were determined by Fisher's PLSD multiple range test.

\section{Results}

Cloning of the 5'-flanking region of the S. aurata mALT gene

A $1540 \mathrm{bp}$ fragment located upstream of the transcription start site of mALT was isolated by chromosome walking on $S$. aurata genomic DNA, using oligonucleotides designed from hepatic mALT cDNA isolated from this species (Metón et al., 2004) (Fig. 1A). Sequence analysis of the 1632 bp 5'-flanking region (-1540 to +92 bp relative to the transcription start site) carried out using the MatInspector program (Cartharius et al., 2005) revealed several putative transcription factor binding sites in the proximal promoter region (Fig. 1A). The nucleotide sequence of the $S$. aurata mALT gene promoter was submitted to the DDBJ/EMBL/GeneBank databases under accession number DQ114990.

Identification of S. aurata mALT promoter 
To determine whether the 5 '-flanking region of the mALT gene contains promoter activity, the isolated $1632 \mathrm{bp}$ fragment was subcloned into the promoterless plasmid pGL3-Basic, upstream of the luciferase reporter gene. HEK293 cells were transiently cotransfected with pGmALT1540 and a lacZ-containing plasmid, which was used as an internal control for transfection efficiency. The cell lysate was assayed for luciferase and $\beta$-galactosidase activity $16 \mathrm{~h}$ after transfection. The pGmALT1540 construct exhibited an 8-fold increase in luciferase activity relative to the promoterless vector, pGL3-Basic (Fig. 1B). This result indicates that the region comprised within 1540 nucleotides upstream from the transcription start site of $S$. aurata mALT contains the core promoter for the basal transcription of mALT.

To further examine the functional regions involved in modulation of basal mALT expression in $S$. aurata, a sequential 5'-deletion analysis of the promoter fragment was carried out. The deleted fragments, with 5 ' ends ranging from -1540 to +62 and $3^{\prime}$ ends at +92 , were fused to the luciferase reporter gene and transfected into HEK293 cells. The expression induction of pGmALT519, pGmALT325, pGmALT153, pGmALT103 and pGmALT49 was between 6- and 11- fold compared to the empty vector. However, no induction of activity was found using the smallest construct (pGmALT+62). These findings indicate that the minimal core promoter of the S. aurata mALT gene is located within 49 bp upstream from the transcriptional start, which suggests that cis-acting elements may be located in this region. Due to the fact that the promoter sequence of piscine mALT has several putative HNF4 $\alpha$ boxes, and that $\mathrm{HNF} 4 \alpha$ is involved in transcriptional regulation of several amino acid metabolism regulatory enzymes (Monaci et al., 1988; Nitsch et al., 1993; Inoue et al., 2002), this study was focused on the effect of HNF4 $\alpha$ on the promoter activity of Sparus aurata mALT. 
Molecular cloning of S. aurata cDNA encoding $H N F 4 \alpha$

A 2341 bp cDNA encoding HNF4 $\alpha$ transcription factor from the kidney of S. aurata was isolated using RT-PCR and RACE PCR techniques. The nucleotide sequence reported for HNF4 $\alpha$ has been deposited in the DDBJ, EMBL and GenBank Nucleotide Sequence Databases under the accession number FJ360721. The 2341-bp HNF4 $\alpha$ cDNA contains a 1365-bp open reading frame (ORF). The initial ATG of the ORF is surrounded by a consensus sequence for initiation of transcription in vertebrates (Kozak, M., 1996). A consensus polyadenylation-like signal (AATAAA) was found 20 bp upstream of the HNF4 $\alpha$ poly $(\mathrm{A}+)$ tail. The deduced amino acid sequence of the cloned HNF4 $\alpha$ predicts a polypeptide of 454 amino acids with a calculated molecular mass of $50.68 \mathrm{kDa}$. To investigate the evolutionary relationships of HNF4a in vertebrates, the inferred amino acid sequence of $S$. aurata HNF4 $\alpha$ was compared with those reported for other vertebrates using pair-wise alignments to further generate a phylogenetic tree (Figs. 2A and 2B). Amongst fish, S. aurata HNF4 $\alpha$ showed higher similarity to Tetraodon nigroviridis (97\% of identity) than to its ortholog from Danio rerio $(93 \%)$. Compared with the peptide sequences from other vertebrates, S. aurata HNF4 $\alpha$ shared $83 \%$ amino acid identity with mammals, $84 \%$ with Gallus gallus and $85 \%$ with Xenopus laevis.

Tissue distribution of $m A L T$ and HNF $4 \alpha$ in S. aurata.

qRT-PCR performed on total RNA isolated from several tissues of fed S. aurata showed that although mALT is ubiquitously expressed, the higher expression is found 
in kidney, followed by liver, and intestine. The mALT expression in kidney, liver and intestine was 10, 5 and 4 times higher respectively, than in spleen (Fig. 3A). The tissue expression profile of HNF4 $\alpha$ shows that is highly expressed in liver, kidney and intestine, as described for other species (Sladek et al., 1990; Taraviras et al., 1994) (Fig. $3 B)$.

HNF4 $\alpha$ transactivates the $S$. aurata mALT promoter

In silico analysis indicated the presence of several putative HNF4 response elements in the $S$. aurata mALT promoter at nucleotide positions -865 to $-845,-411$ to -391 and -59 to -39 upstream of the transcription start site (Fig. 1A). To analyse the effect of HNF4 $\alpha$ on the transcriptional activity of mALT gene, transient transfection experiments were performed in HEK293 cells. Reporter constructs containing sequential 5'-deletions on pGmALT1540 were introduced into HEK293 cells together with an expression plasmid encoding rat or $S$. aurata $\mathrm{HNF} 4 \alpha$. No difference between rat or $S$. aurata $\mathrm{HNF} 4 \alpha$ was found in the transcriptional activation of the mALT promoter. Cotransfection of HNF4 $\alpha$ with reporter constructs equal to or longer than pGmALT103 resulted in a 3- to 5-fold induction of the promoter activity relative to the basal activity of the corresponding promoter construct. The shorter reporter construct that exhibited HNF4 $\alpha$-mediated transactivation (pGmALT103) contained an HNF4 response element at positions -59 to -39 , relative to the transcription start site (Fig. 4). No significant enhancement of promoter activity was detected when pGmALT49, pGmALT +62 or the promoterless vector (pGL3-Basic) was used. The transfection of HEK293 cells with a reporter construct containing a deletion within the region -103 to -49 , (pGmALT1540 $103-49$ ) 
together with HNF4 $\alpha$ expression vectors, abolished the HNF4 $\alpha$ transactivating effect (Fig. 4).

HNF4a binds to the putative HNF4 response element located at positions -63 to -39 of the S. aurata $m A L T$ promoter

Band shift experiments were carried out to assess whether HNF4 $\alpha$ binds to the putative HNF4 response element at position -63 to -39 . Using a probe designed to harbour the putative HNF4 response element (HNF4 $\alpha-66 /-37)$ and nuclear extracts from S. aurata, one major shifted band was observed. A DNA-protein complex with the same mobility was observed when a consensus HNF4 $\alpha$ probe was used (HNF4 $\alpha$-cons). Specificity of HNF4 $\alpha$ binding to the HNF4 response element located at position -63 to -39 of the $S$. aurata mALT gene was validated by competition experiments and by using an HNF4 $\alpha$ antibody. The observed shifted band disappeared in competition experiments performed with a 10 - to 100 -fold molar excess of unlabeled HNF4 $\alpha$-cons. In addition, the HNF4 $\alpha$ antibody abolished the binding of HNF4 $\alpha$ to the probe (Fig. 5A). These data confirmed that HNF4 $\alpha$ binds to the HNF4 $\alpha$ box at position -63 to -39 of the $S$. aurata mALT gene.

Additionally, band shift assays were performed to test whether site-directed mutations in the putative HNF4 response element could prevent the formation of the DNA-protein complex. These assays were carried out using nuclear extracts from $S$. aurata and a labeled probe encompassing nucleotide positions -66 to -37 of $S$. aurata mALT but containing a mutated HNF4 $\alpha$ box (mALT-66/-37mutHNF4 $\alpha$ ). As shown in Fig. 5A, the DNA-protein complex shifted when HNF4 $\alpha$-cons and HNF4 $\alpha-66 /-37$ probes were used, disappeared when the mALT-66/-37mutHNF4 $\alpha$ probe was used. 
Mutating the HNF4 response element abolishes the HNF4a dependent transactivation of the S. aurata mALT gene.

The mutations described for the double-stranded oligonucleotide mALT-66/37 mutHNF4 $\alpha$ used in the band shift assays, were introduced into the promoter construct pGm1540, to generate a reporter construct encompassing a mutated HNF4 response element (pGmALT1540mut). Cotransfection experiments of this construct and the expression vector encoding $S$. aurata HNF4 $\alpha$ were performed in HEK293 cells to assess whether this transcription factor could transactivate mALT gene. As shown in Fig. 5B, introduction of two point mutations in the HNF4 response element located at position 63 to -39 prevented the enhancement of transcriptional activity either by $S$. aurata HNF4 $\alpha$ in transient transfection experiments. These results demonstrated that the HNF4 response element, found at position -63 to -39 upstream of the transcriptional start of the $S$. aurata mALT promoter, is responsible for mALT gene transactivation by HNF4 $\alpha$.

Kinetic properties of S. aurata $m A L T$

S. cerevisiae strain YDR089c was chosen as expression system because it presents a deletion involving the putative yeast mitochondrial ALT gene. Enzyme activity and immunodetectable levels of $S$. aurata mALT were analysed in protein extracts isolated from yeast transformed with pYmALT expression construct. The production of $S$. aurata protein in yeast transformants was checked by Western blot using a polyclonal antibody against $S$. aurata ALT enzymes. Yeast transformants with pYmALT expressed protein with estimated molecular mass of $54 \mathrm{kDa}$ (Fig. 6A). In yeast expressing mALT, 
maximal activity was observed at $\mathrm{pH} 7.22$ and 7.65 for the forward and reverse ALT reaction, respectively.

In yeast expressing mALT, ALT specific activity increased in both forward and reverse reaction compared to cells transformed with pYES2, indicating proper overexpression of the mALT enzyme. The ALT activity was 7-fold higher for the forward reaction than that for the reverse reaction (Fig. 6B).

The kinetic plots for mALT activity as a function of L-alanine or 2-oxoglutarate concentration were hyperbolic. As described for ALTs enzymes from other organisms, double-reciprocal plots indicated that the enzymatic reaction follows a ping-pong mechanism (Figs. 7A and 7B). Km values estimated for L-alanine was $2.22 \mathrm{mM}$ and $0.21 \mathrm{mM}$ for 2-oxoglutarate.

Considering the reverse reaction, the kinetic plots for mALT were hyperbolic when the activity was represented as a function of L-glutamate or pyruvate. $\mathrm{Km}$ values for L-glutamate and pyruvate were $11.30 \mathrm{mM}$ and $0.32 \mathrm{mM}$, respectively (Figs. 7C and 7D).

Nutritional and hormonal regulation of mALT and HNF4a gene expression in the kidney of S. aurata

Having concluded that HNF4 $\alpha$ binds to and transactivates the mALT promoter, we studied its role in the transcriptional expression of mALT in kidney under different nutritional and hormonal conditions. In 18 days starved fish, qRT-PCR assays revealed that the mALT mRNA levels significantly decreased up to $44 \%$ of the values found in control fish (Fig. 8A). Consistent with these results, the HNF4 $\alpha$ mRNA levels showed also a tendency to decrease in starved animals (Fig. 8B). 
Streptozotocin (STZ), a glucosamine-nitrosourea derivative that causes $\beta$-cell necrosis, is widely used to generate diabetic animal models (Junod et al., 1969; Wilson and Leiter, 1990). As previously showed, thirty hours after intraperitoneal administration of STZ to S. aurata, glycaemia increased 2-fold compared to fish administered saline, meanwhile treatment with insulin reduced the glycaemia levels (Anemaet et al., 2008). In the present study, qRT-PCR analysis performed on kidney of STZ-treated fish, indicated that mALT and HNF4 $\alpha$ mRNA levels were 3.4- and 5.8-fold lower, respectively, compared with control fish (Figs. 8C and 8D). However, both mALT and HNF4 $\alpha$ mRNA remained unchanged in insulin-treated fish (Figs. 8C and 8D).

\section{Discussion}

HNF4 plays a key role for the accurate expression of genes involved in amino acid and protein metabolism (Monaci et al., 1988; Kimura et al., 1993; Inoue et al., 2002). There is evidence that HNF4 $\alpha$ gene expression is reduced in the kidney of patients with diabetic nephropathy (Niehof and Borlak, 2008) and abnormal mitochondrial metabolism and $\mathrm{HNF} 4 \alpha$ disfunction lead to insulin-resistant states (Mohlke and Boehnke, 2005; MacDonald et al., 2009). Mitochondria are becoming increasingly important because of their central role in cell energy balance. In this regard, ALT plays an important function as a molecular link between carbohydrate and amino acid metabolism. Our previous studies reported the first animal amino acid sequence of a mitochondrial ALT (Metón et al., 2004). In humans and mice, two ALT isoforms, ALT1 and ALT2, each encoded by a different gene, have been cloned (Sohocki et al., 1997; Yang et al., 2002; Jadhao et al., 2004). The human ALT1 gene 
was cloned from the amino acid sequence of liver cytosolic ALT. The subcellular localization of ALT2 was reported to have mitochondrial localization (Glinghammar et al., 2009). In the present study we have characterized the expression of HNF4 $\alpha$ and analyzed its effect on the transcriptional control of mALT gene in the kidney of $S$. aurata. We report for the first time the characterization of the promoter region of a mitochondrial ALT gene and the involvement of HNF4 $\alpha$ in the transcription of this gene. In addition, we report kinetic data for mALT enzyme and studied the influence of different hormonal and nutritional conditions on mALT and HNF4 $\alpha$ expression in the kidney of $S$. aurata.

To study the transcriptional regulation of mALT, we isolated and characterized the promoter region of mALT from $S$. aurata. The functionality of the putative promoter region of fish mALT was tested by transient transfection of human kidneyderived HEK293 cells. Cells were transfected with fusion constructs containing sequencial 5'-deletions of the $1632 \mathrm{bp}$ fragment promoter isolated by chromosome walking. We found that the promoter region within $49 \mathrm{bp}$ upstream from the transcription start site was essential for transcriptional basal activity of mALT and therefore constitutes the core promoter of this gene. Due to the presence of several putative HNF4 binding sites and the fact that there is increasing evidence for the involvement of $\mathrm{HNF} 4 \alpha$ in the transcriptional control of several regulatory enzymes of protein metabolism (Nitsch et al., 1993; Nishiyori et al., 1994), we considered that HNF4 $\alpha$ could play a role in the transcriptional control of mALT gene.

A cDNA encoding the $\mathrm{HNF} 4 \alpha$ transcription factor protein was isolated from kidney of $S$. aurata. The 454-amino acid deduced protein is homologous to the human HNF4 $\alpha 1$ isoform. A comparison of the HNF4 $\alpha$ sequence from $S$. aurata to that reported for other vertebrates revealed a high degree of conservation among fish, amphibians, 
birds, and mammals. All residues reported as being important for the structure and function of AF-1, AF-2 and LBD domains were fully conserved in S. aurata HNF4 $\alpha$ (Green et al., 1998; Kistanova et al., 2001; Eeckhoute et al., 2003b; Aggelidou et al., 2004; Iordanidou et al., 2005). The results of the phylogenetic tree analysis are consistent with the taxonomic hierarchy. Regarding teleost fish, S. aurata and $T$. nigroviridis belong to the same superorder (Acanthopterygii), while D. rerio belongs to the superorder Ostariophysi. Moreover, our finding that, in S. aurata HNF4 $\alpha$ is mainly expressed in kidney, liver and intestine is consistent with the tissue distribution found in humans and rats (Sladek et al., 1990; Taraviras et al., 1994). The S. aurata tissue distribution of HNF $4 \alpha$ correlated with that observed for mALT.

In this study, we demonstrated that HNF4 $\alpha$ interacts specifically with the HNF4 response element located between -63 and -39 bp upstream from the transcription start site of the $S$. aurata mALT gene promoter. Transient transfection studies carried out in HEK293 cells allowed us to demonstrate that HNF4 $\alpha$ confers an activating signal by binding to an HNF4 response element in the $S$. aurata mALT promoter. Mutations in the HNF4 $\alpha$ box abolished binding of HNF4 $\alpha$ to the mutated site, and as a result, HNF4 $\alpha$ did not longer enhance the transcription of mALT gene. Furthermore, introduction of the same mutations into the pGm1540 construct, abolished the transcriptional activation induced by HNF4 $\alpha$. These findings confirm that HNF4 $\alpha$ transactivates the mALT promoter. Similarly, HNF4 $\alpha$ has been reported to transactivate other genes involved in amino acid and protein metabolism such as tyrosine aminotransferase, ornithine aminotransferase and alpha 1-antitrypsin (Monaci et al., 1988; Kimura et al., 1993; Inoue et al., 2002). Interestingly, HNF4 $\alpha$ did not enhance the transcriptional activity of the previously cloned $S$. aurata cALT promoter (Anemaet et al., 2010) in HEK293 cells (data not shown), which suggest that HNF4 $\alpha$ exerts a specific effect on the mALT gene. 
Kinetic characterization of $S$. aurata mALT indicates that this enzyme follows a ping-pong mechanism, as previously described for other ALT isoenzymes. The $K_{\mathrm{m}}$ values for L-alanine, 2-oxoglutarate, L-glutamate and pyruvate of $S$. aurata mALT are in the range of those described for mitochondrial ALT in other animals (Swick et al., 1965; Hayashi et al., 2003; Glinghammar et al., 2009). Possibly mALT would preferably catalyze the forward reaction as the $V_{\max } / K_{\mathrm{m}}$ ratio for L-alanine was higher than that for L-glutamate. Moreover, values of ALT activity for the forward reaction were 7-fold higher than for the reverse reaction. Similar as in S. aurata, the kinetics studies of mALT in gill of the brackish-water bivalve Corbicula japonica lead Hayashi (Hayashi, 1993) to the observation that mALT activity preferentially catalyzes the reaction in the pyruvate-forming direction. The same relationships were obtained for rat liver (Swick, 1965; Walker, 1991). The main difference between kinetics for cytosolic and mitochondrial $S$. aurata ALT isoforms was found in the $K_{\mathrm{m}}$ value for 2-oxoglutarate which was 4-fold higher for mALT. However, if this kinetic feature has a consequence in the direction of the reaction or if it results from a putative difference in the 2oxoglutarate concentration between cytosol and mitochondria remains unknown.

Amino acids are important substrates in the fish kidney for both oxidation and gluconeogenesis (Jürss and Bastrop, 1995). The rate of oxidation of alanine was reported to be more than 10 -fold higher than the rate of incorporation into glucose in Atlantic salmon kidney (Mommsen et al., 1985). To understand the role of mALT and HNF4 $\alpha$ gene in the kidney of $S$. aurata, we addressed the nutritional and hormonal regulation of both proteins at the mRNA level. Our results revealed that starvation resulted in decreased levels of mALT and HNF4 $\alpha$ in kidney of $S$. aurata. Recently, Anemaet et al. (2008) have shown that the mRNA levels of cALT1 also decreased in liver of S. aurata submitted to starvation. In liver, decreased ALT activity was reported 
in starved fish (Metón et al., 1999). Viollet et al. (1997), in studies carried out with Ltype pyruvate kinase, showed that HNF4 DNA binding activity in nuclear extracts of fasted rat liver was markedly reduced in comparison with that of refed rat liver. Consistent with down-regulation of mALT expression in starvation, STZ-treatment, a nutritional condition associated with gluconeogenesis, caused a decrease in mALT and HNF4 $\alpha$ mRNA levels. Similarly, Niehof and Borlak (2008) also reported a decrease of HNF4 $\alpha$ expression in kidney of STZ-treated rats. Since down-regulation of HNF4 $\alpha$ expression correlated with low mRNA levels of mALT in kidney of starved and STZtreated $S$. aurata, our findings point to an important role of HNF4 $\alpha$ in the transcriptional regulation of mALT gene. Moreover, these observations suggest that the expression of mALT in kidney might be mainly involved in the oxidation of amino acids for energetic pourposes instead of gluconeogenesis.

In conclusion, besides reporting the first mALT promoter, our results indicate that HNF4 $\alpha$ plays an important role in the transcriptional regulation of mALT gene in kidney of starved- and STZ-treated $S$. aurata. We hypothesize that mALT exerts a major role in oxidazing dietary amino acids. With the aim of increasing the protein sparing effect and the use of alternative nutrients in the diet supplied to carnivorous fish in culture, future studies will be addresed to analyse the metabolic effects after overexpression or down-regulation of ALT isoforms.

\section{Acknowledgements}

This work was supported by the MCYT (Spain) BIO2006-01857 and MICINN (Spain) BIO2009-07589 grants. 


\section{References}

Aggelidou, E., Iordanidou, P., Tsantili, P., Papadopoulos, G. \& Hadzopoulou-Cladaras, M. (2004). Critical role of residues defining the ligand binding pocket in hepatocyte nuclear factor-4alpha. J Biol Chem, 279: 30680-30688.

Andrews, N.C. \& Faller, D.V. (1991). A rapid micropreparation technique for extraction of DNA-binding proteins from limiting numbers of mammalian cells. Nucleic Acids Res, 19: 2499.

Anemaet, I.G., Metón, I., Salgado, M.C., Fernández, F. \& Baanante, I.V. (2008). A novel alternatively spliced transcript of cytosolic alanine aminotransferase gene associated with enhanced gluconeogenesis in liver of Sparus aurata. Int $J$ Biochem Cell Biol, 40: 2833-2844.

Anemaet, I.G., González, J.D., Salgado, M.C., Giralt, M., Fernández, F., Baanante, I.V. \& Metón, I. (2010). Transactivation of cytosolic alanine aminotransferase gene promoter by p300 and c-Myb. J Mol Endocrinol, 45: 119-132.

Bartoov-Shifman, R., Hertz, R., Wang, H., Wollheim, C.B., Bar-Tana, J. \& Walker, M.D. (2002). Activation of the insulin gene promoter through a direct effect of hepatocyte nuclear factor 4 alpha. J Biol Chem, 277: 25914-25919.

Bradford, M.M. (1976). A rapid and sensitive method for the quantitation of microgram quantities of protein utilizing the principle of protein-dye binding. Anal Biochem, 72: 248-254.

Cartharius, K., Frech, K., Grote, K., Klocke, B., Haltmeier, M., Klingenhoff, A., Frisch, M., Bayerlein, M. \& Werner, T. (2005). MatInspector and beyond: promoter analysis based on transcription factor binding sites. Bioinformatics, 21: 29332942. 
Cowey, C.B. \& Walton, M.J. (1989). Intermediary metabolism. IN Halver, J.E. (Ed.) Fish Nutrition. San Diego: Academic Press.

De Rosa, G. \& Swick, R.W. (1975). Metabolic implications of the distribution of the alanine aminotransferase isoenzymes. J Biol Chem 250: 7961-7967.

Duda, K., Chi, Y.I. \& Shoelson, S.E. (2004). Structural basis for HNF-4alpha activation by ligand and coactivator binding. J Biol Chem, 279: 23311-23316.

Eeckhoute, J., Moerman, E., Bouckenooghe, T., Lukoviak, B., Pattou, F., Formstecher, P., Kerr-Conte, J., Vandewalle, B. \& Laine, B. (2003a). Hepatocyte nuclear factor 4 alpha isoforms originated from the $\mathrm{P} 1$ promoter are expressed in human pancreatic beta-cells and exhibit stronger transcriptional potentials than P2 promoter-driven isoforms. Endocrinology, 144: 1686-1694.

Eeckhoute, J., Oxombre, B., Formstecher, P., Lefebvre, P. \& Laine, B. (2003b). Critical role of charged residues in helix 7 of the ligand binding domain in Hepatocyte Nuclear Factor 4alpha dimerisation and transcriptional activity. Nucleic Acids Res, 31: 6640-6650.

Fernández, F., Miquel, A.G., Córdoba, M., Varas, M., Metón, I., Caseras, A. \& Baanante, I.V. (2007). Effects of diets with distinct protein-to-carbohydrate ratios on nutrient digestibility, growth performance, body composition and liver intermediary enzyme activities in gilthead sea bream (Sparus aurata, L.) fingerlings. Journal of Experimental Marine Biology and Ecology, 343: 1-10.

Fynn-Aikins, K., Hughes, S.G. \& Vandenberg, G.W. (1995). Protein retention and liver aminotransferase activities in Atlantic salmon fed diets containing different energy sources. Comp Biochem Physiol A - Comp Physiol, 111: 163-170. 
Garrison, W.D., Battle, M.A., Yang, C., Kaestner, K.H., Sladek, F.M. \& Duncan, S.A. (2006). Hepatocyte nuclear factor 4alpha is essential for embryonic development of the mouse colon. Gastroenterology, 130: 1207-1220.

Glinghammar, B., Rafter, I., Lindström, A.K., Hedberg, J.J., Andersson, H.B., Lindblom, P., Berg, A.L. \& Cotgreave, I. (2009). Detection of the mitochondrial and catalytically active alanine aminotransferase in human tissues and plasma. Int J Mol Med, 23: 621-631.

Gray, S., Wang, B., Orihuela, Y., Hong, E.G., Fisch, S., Haldar, S., Cline, G.W., Kim, J.K., Peroni, O.D., Kahn, B.B. \& Jain, M.K. (2007). Regulation of gluconeogenesis by Kruppel-like factor 15. Cell Metab, 5: 305-312.

Green, V.J., Kokkotou, E. \& Ladias, J.A. (1998). Critical structural elements and multitarget protein interactions of the transcriptional activator AF-1 of hepatocyte nuclear factor 4. J Biol Chem, 273: 29950-29957.

Gupta, R.K., Vatamaniuk, M.Z., Lee, C.S., Flaschen, R.C., Fulmer, J.T., Matschinsky, F.M., Duncan, S.A. \& Kaestner, K.H. (2005). The MODY1 gene HNF-4alpha regulates selected genes involved in insulin secretion. J Clin Invest, 115: 10061015.

Gupta, R.K., Gao, N., Gorski, R.K., White, P., Hardy, O.T., Rafiq, K., Brestelli, J.E., Chen, G., Stoeckert, C.J., Jr. \& Kaestner, K.H. (2007). Expansion of adult betacell mass in response to increased metabolic demand is dependent on HNF4alpha. Genes Dev, 21: 756-769.

Hadzopoulou-Cladaras, M., Kistanova, E., Evagelopoulou, C., Zeng, S., Cladaras, C. \& Ladias, J.A. (1997). Functional domains of the nuclear receptor hepatocyte nuclear factor 4. J Biol Chem, 272: 539-550. 
Hayashi, Y.S. (1993). Alanine aminotransferase from gill tissue of the brackish-water bivalve Corbicula japonica (Prime): Subcellular localization and some enzymatic properties. Journal of Experimental Marine Biology and Ecology, 170: 45-54.

Hayhurst, G.P., Lee, Y.H., Lambert, G., Ward, J.M. \& Gonzalez, F.J. (2001). Hepatocyte nuclear factor 4alpha (nuclear receptor 2A1) is essential for maintenance of hepatic gene expression and lipid homeostasis. Mol Cell Biol, 21: 1393-1403.

Hemre, G.I., Mommsen, T. \& Krogdahl, Å. (2002). Carbohydrates in fish nutrition: effects on growth, glucose metabolism and hepatic enzymes. Aquaculture Nutrition, 8: 175-194.

Inoue, Y., Hayhurst, G.P., Inoue, J., Mori, M. \& Gonzalez, F.J. (2002). Defective ureagenesis in mice carrying a liver-specific disruption of hepatocyte nuclear factor 4alpha (HNF4alpha ). HNF4alpha regulates ornithine transcarbamylase in vivo. J Biol Chem, 277: 25257-25265.

Iordanidou, P., Aggelidou, E., Demetriades, C. \& Hadzopoulou-Cladaras, M. (2005). Distinct amino acid residues may be involved in coactivator and ligand interactions in hepatocyte nuclear factor-4alpha. J Biol Chem, 280: 2181021819

Jadhao, S.B., Yang, R.Z., Lin, Q., Hu, H., Anania, F.A., Shuldiner, A.R. \& Gong, D.W. (2004). Murine alanine aminotransferase: cDNA cloning, functional expression, and differential gene regulation in mouse fatty liver. Hepatology, 39: 12971302. 
Jiang, G. \& Sladek, F.M. (1997). The DNA binding domain of hepatocyte nuclear factor 4 mediates cooperative, specific binding to DNA and heterodimerization with the retinoid X receptor alpha. J Biol Chem, 272: 1218-1225.

Junod, A., Lambert, A.E., Stauffacher, W. \& Renold, A.E. (1969). Diabetogenic action of streptozotocin: relationship of dose to metabolic response. J Clin Invest, 48: 2129-2139.

Jürss, K. \& Bastrop, R. (1995). Amino acid metabolism in fish. Biochemistry and Molecular Biology of Fishes, 4: 159-189.

Kardassis, D., Falvey, E., Tsantili, P., Hadzopoulou-Cladaras, M., Zannis, V. (2002). Direct physical interactions between HNF-4 and Sp1 mediate synergistic transactivation of the apolipoprotein CIII promoter. Biochemistry 41: 12171228.

Kimura, A., Nishiyori, A., Murakami, T., Tsukamoto, T., Hata, S., Osumi, T., Okamura, R., Mori, M. \& Takiguchi, M. (1993). Chicken ovalbumin upstream promotertranscription factor (COUP-TF) represses transcription from the promoter of the gene for ornithine transcarbamylase in a manner antagonistic to hepatocyte nuclear factor-4 (HNF-4). J Biol Chem, 268: 11125-11133.

Kistanova, E., Dell, H., Tsantili, P., Falvey, E., Cladaras, C. \& Hadzopoulou-Cladaras, M. (2001). The activation function-1 of hepatocyte nuclear factor-4 is an acidic activator that mediates interactions through bulky hydrophobic residues. Biochem J, 356: 635-642.

Li, J., Ning, G. \& Duncan, S.A. (2000). Mammalian hepatocyte differentiation requires the transcription factor HNF-4alpha. Genes Dev, 14: 464-474. 
Macdonald, M., Longacre, M., Langberg, E.C., Tibell, A., Kendrick, M., Fukao, T. \& Ostenson, C.G. (2009). Decreased levels of metabolic enzymes in pancreatic islets of patients with type 2 diabetes. Diabetologia, 52: 1087-1091.

Metón, I., Mediavilla, D., Caseras, A., Cantó, E., Fernández, F. \& Baanante, I.V. (1999). Effect of diet composition and ration size on key enzyme activities of glycolysis-gluconeogenesis, the pentose phosphate pathway and amino acid metabolism in liver of gilthead sea bream (Sparus aurata). British Journal of Nutrition, 82: 223-232.

Metón, I., Egea, M., Fernández, F., Eraso, M.C. \& Baanante, I.V. (2004). The Nterminal sequence directs import of mitochondrial alanine aminotransferase into mitochondria. FEBS Lett, 566: 251-254.

Metón, I., Egea, M., Anemaet, I.G., Fernández, F. \& Baanante, I.V. (2006). Sterol regulatory element binding protein-1a transactivates 6-phosphofructo-2kinase/fructose-2,6-bisphosphatase gene promoter. Endocrinology, 147: 34463456.

Miura, A., Yamagata, K., Kakei, M., Hatakeyama, H., Takahashi, N., Fukui, K., Nammo, T., Yoneda, K., Inoue, Y., Sladek, F.M., Magnuson, M.A., Kasai, H., Miyagawa, J., Gonzalez, F.J. \& Shimomura, I. (2006). Hepatocyte nuclear factor-4alpha is essential for glucose-stimulated insulin secretion by pancreatic beta-cells. J Biol Chem, 281: 5246-5257.

Mohlke, K.L. \& Boehnke, M. (2005). The role of HNF4A variants in the risk of type 2 diabetes. Curr Diab Rep, 5: 149-156.

Mommsen, T.P., Walsh, P.J. \& Moon, T.W. (1985). Gluconeogenesis in hepatocytes and kidney of Atlantic salmon. Mol Physiol, 8: 89-100. 
Monaci, P., Nicosia, A. \& Cortese, R. (1988). Two different liver-specific factors stimulate in vitro transcription from the human alpha 1-antitrypsin promoter. Embo J, 7: 2075-2087.

Moon, T.W. (2001). Glucose intolerance in teleost fish: fact or fiction? Comp Biochem Physiol B: Biochem Mol Biol, 129: 243-249.

Niehof, M. \& Borlak, J. (2008). HNF4 $\alpha$ and the Ca-channel TRPC1 are novel disease candidate genes in diabetic nephropathy. Diabetes, 57: 1069-1077.

Nishiyori, A., Tashiro, H., Kimura, A., Akagi, K., Yamamura, K., Mori, M. \& Takiguchi, M. (1994). Determination of tissue specificity of the enhancer by combinatorial operation of tissue-enriched transcription factors. Both HNF-4 and $\mathrm{C} / \mathrm{EBP}$ beta are required for liver-specific activity of the ornithine transcarbamylase enhancer. J Biol Chem, 269: 1323-1331.

Nitsch, D., Boshart, M. \& Schutz, G. (1993). Activation of the tyrosine aminotransferase gene is dependent on synergy between liver-specific and hormone-responsive elements. Proc Natl Acad Sci U S A, 90: 5479-5483.

Parviz, F., Matullo, C., Garrison, W.D., Savatski, L., Adamson, J.W., Ning, G., Kaestner, K.H., Rossi, J.M., Zaret, K.S. \& Duncan, S.A. (2003). Hepatocyte nuclear factor 4alpha controls the development of a hepatic epithelium and liver morphogenesis. Nat Genet, 34: 292-296.

Salgado, M.C., Metón, I., Egea, M. \& Baanante, I.V. (2004). Transcriptional regulation of glucose-6-phosphatase catalytic subunit promoter by insulin and glucose in the carnivorous fish, Sparus aurata. J Mol Endocrinol, 33: 783-795.

Sánchez-Muros, M.J., García-Rejón, L., García-Salguero, L., De La Higuera, M. \& Lupiáñez, J.A. (1998). Long-term nutritional effects on the primary liver and kidney metabolism in rainbow trout. Adaptive response to starvation and a high- 
protein, carbohydrate-free diet on glutamate dehydrogenase and alanine aminotransferase kinetics. The International Journal of Biochemistry \& Cell Biology, 30: 55-63.

Schrem, H., Klempnauer, J. \& Borlak, J. (2002). Liver-enriched transcription factors in liver function and development. Part I: the hepatocyte nuclear factor network and liver-specific gene expression. Pharmacol Rev, 54: 129-158.

Sladek, F.M., Zhong, W.M., Lai, E. \& Darnell, J.E., Jr. (1990). Liver-enriched transcription factor HNF-4 is a novel member of the steroid hormone receptor superfamily. Genes Dev, 4: 2353-2365.

Sladek, F.M. \& Seidel, S.D. (2001). Hepatocyte nuclear factor 4 alpha. IN Burris, T. \& Mccabe, E.R.B. (Eds.) Nuclear Receptors and Disease. London: Academic Press.

Sohocki, M.M., Sullivan, L.S., Harrison, W.R., Sodergren, E.J., Elder, F.F.B., Weinstock, G., Tanase, S. \& Daiger, S.P. (1997). Human Glutamate Pyruvate Transaminase (GPT): Localization to 8q24.3, cDNA and Genomic Sequences, and Polymorphic Sites. Genomics, 40: 247-252.

Stoffel, M. \& Duncan, S.A. (1997). The maturity-onset diabetes of the young (MODY1) transcription factor HNF4alpha regulates expression of genes required for glucose transport and metabolism. Proc Natl Acad Sci U S A, 94: 13209-13214.

Swick, R.W., Barnstein, P.L., Stange, J.L. (1965). The metabolism of mitochondrial proteins. I. Distribution and characterization of the isozymes of alanine aminotransferase in rat liver. J Biol Chem, 240: 3334-3340.

Taraviras, S., Monaghan, A.P., Schutz, G. \& Kelsey, G. (1994). Characterization of the mouse HNF-4 gene and its expression during mouse embryogenesis. Mech Dev, 48: 67-79. 
Thulin, P., Rafter, I., Stockling, K., Tomkiewicz, C., Norjavaara, E., Aggerbeck, M., Hellmold, H., Ehrenborg, E., Andersson, U., Cotgreave, I. \& Glinghammar, B. (2008). PPARalpha regulates the hepatotoxic biomarker alanine aminotransferase (ALT1) gene expression in human hepatocytes. Toxicol Appl Pharmacol, 231: 1-9.

Viollet, B., Kahn, A. \& Raymondjean, M. (1997). Protein kinase A-dependent phosphorylation modulates DNA-binding activity of hepatocyte nuclear factor 4 . Mol Cell Biol, 17: 4208-4219.

Walker, J., Barrett, J. (1991). Studies on alanine aminotransferase in nematodes. Int J Parasitol, 21:377-380.

Wilson, G.L. \& Leiter, E.H. (1990). Streptozotocin interactions with pancreatic beta cells and the induction of insulin-dependent diabetes. Curr Top Microbiol Immunol, 156: 27-54.

Yang, R.-Z., Blaileanu, G., Hansen, B.C., Shuldiner, A.R. \& Gong, D.-W. (2002). cDNA Cloning, Genomic Structure, Chromosomal Mapping, and Functional Expression of a Novel Human Alanine Aminotransferase. Genomics, 79: 445450. 


\section{Figure captions}

Fig. 1 Sequence analysis of the 5' flanking region of mALT gene and deletion analysis and promoter activity of the 5'-flanking region of $S$. aurata mALT gene in HEK293 cells. (A) Sequence analysis of the 5'-flanking region of the S. aurata mALT gene. The upstream sequence isolated by chromosome walking is shown in capitals. The arrow indicates the transcription start site. The translation start codon ATG is in boldface and underlined. Several putative binding sites for transcription factors are boxed. (B) The top left part represents genomic organization of the 5'-flanking region of $S$. aurata mALT gene. Relevant restriction sites are indicated. Nucleotide numbering starts with +1 , corresponding to the transcription initiation site. The $S$. aurata mALT promoter fragments having varying $5^{\prime}$ ends and an identical $3^{\prime}$ end (+92) were fused to the luciferase reporter gene in pGL3-Basic vector. The constructs were transfected into HEK293 cells along with CMV- $\beta$ to normalise for transfection efficiency. Luciferase activity is expressed as a fold increase over promoterless reporter plasmid pGL3-Basic. Results presented are the mean \pm S.D. from four independent experiments performed in duplicate.

Fig. 2 Multiple alignment and phylogenetic tree of HNF4 $\alpha$ sequences. (A) Multiple alignment of the predicted amino acid sequences for $S$. aurata HNF4 $\alpha$ and those reported for other animals. Alignment was made using ClustalW program. Black, identical amino acid residues; grey, conservative amino acid substitutions. GenBank

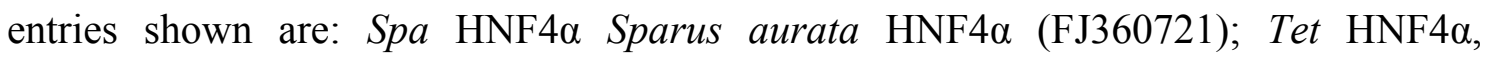
Tetraodon nigroviridis $\mathrm{HNF} 4 \alpha$ (CAG03838); Dan $\mathrm{HNF} 4 \alpha$, Danio rerio $\mathrm{HNF} 4 \alpha$ (NP 


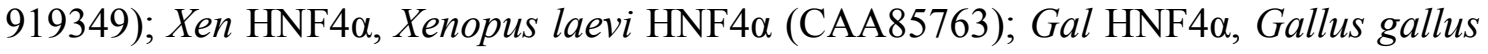
HNF4 $\alpha$ (NP 001026026); Rat HNF4 $\alpha$, Rattus rattus HNF4 $\alpha$ (CAA40412); Bos HNF4 $\alpha$, Bos taurus HNF4a (NP 001015557) and Hum HNF4 $\alpha$, Homo sapiens HNF4 $\alpha$ (CAA61133). (B) Phylogenetic tree for HNF4a. The phylogenetic tree was constructed using the TreeTop phylogenetic tree prediction system (http://www.genebee.msu.su/services/ phtreereduced.html) based in the multiple alignment.

Fig. 3 Tissue distribution of $S$. aurata mALT and HNF4 $\alpha$. Total RNA obtained from liver (L), brain (B), skeletal muscle $(\mathrm{M})$, heart $(\mathrm{H})$, intestine $(\mathrm{I})$, kidney $(\mathrm{K})$, spleen $(\mathrm{S})$, gill $(\mathrm{G})$ and fat $(\mathrm{F})$ of fed fish was reverse transcribed and submitted to qRT-PCR using specific primer pairs for mALT, HNF4 $\alpha$ or ribosomal $18 \mathrm{~s}$ genes. The graph represents mALT (A) or HNF4 $\alpha$ (B) mRNA levels relative to ribosomal 18s mRNA in the same sample \pm S.D. Two different samples were analyzed, each sample was a pool of four to five different fish tissue samples. The spleen mALT or HNF4 $\alpha$ mRNA levels relative to ribosomal 18s mRNA were set as 1 .

Fig. 4 HNF4 $\alpha$ transactivates $S$. aurata mALT promoter in HEK293 cells. HEK293 cells were transfected with the promoter constructs pGmALT1540, pGmALT519, pGmALT325, pGmALT153, pGmALT103, pGmALT49, $\quad$ pGmALT+62, pGmALT1540 $103-49$ or pGL3-Basic, with or without an expression plasmid encoding either $S$. aurata or rat HNF4 $\alpha$. The promoter activity for cells transfected with the constructs alone was set at 1 . The results presented are means \pm S.D. from two independent duplicate experiments. 
Fig. $5 \mathrm{HNF} 4 \alpha$ binds to $S$. aurata mALT promoter. (A) The figure shows an electrophoretic mobility shift assay using nuclear extracts from S. aurata (NE) incubated with labeled oligonucleotides HNF4 $\alpha$-cons (lanes 1-5), mALT-66/-37 (lanes 6-11) or mALT-66/-37mutHNF4 $\alpha$ (lane 12). Lanes 1 and 6 contained no extract. Lanes 2 and 7 show binding of nuclear proteins to the labeled probes in the absence of competitor. Lanes 3, 8; 4, 9 and 5, 10 show competition effect with 10-; 30- and 100fold molar excess, respectively, of unlabeled double-stranded HNF4 $\alpha$-cons. Lane 11 shows a supershift assay using nuclear extracts incubated with labeled oligonucleotide mALT-66/-37 in the presence of antibody against HNF4 $\alpha$ (Ab HNF4 $\alpha$ ). Lane 12 shows a shift analysis performed with labeled oligonucleotide mALT-66/-37mutHNF4 $\alpha$ incubated in presence of $S$. aurata nuclear extracts. DNA-protein complexes are indicated by an arrow. (B) Mutations in the HNF4 $\alpha$ box abolish transactivation of mALT promoter by HNF4a. HEK293 cells were transfected with the promoter constructs pGmALT103, pGmALTmut103 or pGL3-Basic, with or without an expression plasmid encoding $S$. aurata HNF4a. The promoter activity displayed by the constructs alone was set at 1 . Results presented are means \pm S.D. from two independent duplicate experiments.

Fig. 6 Expression of mALT in yeast. (A) Immunodetectable level of mALT in protein extracts obtained from yeast grown $24 \mathrm{~h}$ at $30{ }^{\circ} \mathrm{C}$ after transformation with the empty vector (pYES2) or pYmALT. (B) Forward and reverse ALT enzyme activities were determined with the desalted protein extracts from yeast expressing the empty vector (pYES2) or pYmALT. Data are expressed as mean \pm S.D. of values corresponding to four to six desalted yeast protein extracts. 
Fig. 7 Kinetics for 2-oxoglutarate, L-alanine, pyruvate and L-glutamate of S. aurata mALT. (A) Saturation kinetics for 2-oxoglutarate of mALT. ALT activity was assayed (forward reaction) by varying 2-oxoglutarate levels in the presence of $0.75 \mathrm{mM}(\bullet), 2$ $\mathrm{mM}(\mathrm{\circ})$ or $10 \mathrm{mM}(\mathbf{\square})$ L-alanine. (B) Saturation kinetics for L-alanine of mALT. ALT activity was assayed (forward reaction) by varying L-alanine levels in the presence of $0.1 \mathrm{mM}(\bullet), 0.25 \mathrm{mM}(\circ)$, or $10 \mathrm{mM}(\mathbf{\bullet})$ 2-oxoglutarate. (C) Saturation kinetics for pyruvate of mALT. ALT activity was assayed (reverse reaction) by varying pyruvate levels in the presence of $10 \mathrm{mM}(\bullet), 25 \mathrm{mM}(\mathrm{\circ})$ or $50 \mathrm{mM}(\boldsymbol{\bullet})$ L-glutamate. (D) Saturation kinetics for L-glutamate of mALT. ALT activity was assayed (reverse reaction) by varying L-glutamate levels in the presence of $1 \mathrm{mM}(\bullet), 3 \mathrm{mM}(\circ)$ or 12 $\mathrm{mM}(\boldsymbol{\square})$ pyruvate. Double-reciprocal plots are representative of experiments performed with two different protein extracts isolated from yeast expressing mALT.

Fig. 8 Effect of different nutritional and hormonal conditions on mALT and HNF4 $\alpha$ mRNA expression in kidney of $S$. aurata. Effect of starvation on mALT (A) and HNF4 $\alpha$ (B) mRNA levels in kidney of $S$. aurata. The average of three independent qRT-PCR assays performed on total RNA isolated from kidney of fed and 19 d-starved fish is shown. mALT and HNF4 $\alpha$ mRNA levels relative to ribosomal $18 \mathrm{~s}$ mRNA are expressed as mean \pm S.D. of four pools of two to three kidney samples. Effect of insulin and streptozotocin on mALT (C) and HNF4 $\alpha$ (D) mRNA levels in kidney of $S$. aurata. Average value of three independent real-time PCR assays performed on total RNA isolated from kidney of fish $6 \mathrm{~h}$ after treatment with saline (control), insulin (10 U/kg fish) or $30 \mathrm{~h}$ after treatment with streptozotocin $(600 \mathrm{mg} / \mathrm{Kg}$ fish) is shown. mALT and HNF4 $\alpha$ mRNA levels relative to ribosomal $18 \mathrm{~s}$ mRNA are expressed as mean \pm S.D. of 
four pools of two to three kidney samples. Statistical significance related to control animals is indicated as follows: ${ }^{* *} P<0.01$. 
Table 1.

Primers used in the present study.

\begin{tabular}{|c|c|c|}
\hline Primer & Sequence (5' to 3 ') & Maps to \\
\hline MC01 & GACAGCAGCTGCATCCTTGTAGCCGAC & mALT,$+101 /+126$ \\
\hline MC02 & CACGGCGAGTTGGGTGACTTTTAAAGCCTC & mALT, $+63 /+92$ \\
\hline $\mathrm{MC} 03$ & CTAGTAGTCTGTCGATGGTTGGGGTCAG & mALT, $-724 /-697$ \\
\hline $\mathrm{MC04}$ & GGGGTCAGACCTGAATACACTACAGGAC & mALT, $-744 /-717$ \\
\hline MC05 & GGAAGCTTCACGGCGAGTTGGGTGAC & mALT, $+75 /+92$ \\
\hline MC06 & GGACGCGTAAAAGTCTTTCAAATATCTG & mALT, $-820 /-801$ \\
\hline MC07 & GGACGCGTCCCACTTTTTATTCGGAG & mALT, $-103 /-96$ \\
\hline MC08 & GGACGCGTGGTCTGAGTCATTTTTAG & mALT, $-49 /-29$ \\
\hline \multirow[t]{3}{*}{ MC09 } & GGCACGTGCGTGTGTGGATGCGAGCAGGGTCTGA & mALT, $-150 /-104$ \\
\hline & AGAGACGCTCTGAGAATTTGTGGTCTGAGTCAGTA & and $-49 /-29$ \\
\hline & TTTTTAG & \\
\hline \multirow[t]{3}{*}{ MC10 } & GGTCTGAAGAGACGCTCTGAGAATTTGTCCCACTT & mALT, $-131 /-27$ \\
\hline & TTTATTCGGAGCCCCGTTAGCTCTTCCCCCGCTCTG & \\
\hline & AGCGGTCCACACGTCTGAGTCAGTATTTTTAGG & \\
\hline MC11 & GAGTCCATGAAGCAGCAGCTG & $\mathrm{HNF} 4 \alpha,+576 /+596$ \\
\hline $\mathrm{MC} 12$ & GAACCAGGTGAGGGTGCAGAG & HNF $4 \alpha,+1171 /+1191$ \\
\hline MC13 & CCAGGGTCCGCTCACTGAT & mALT,$+195 /+214$ \\
\hline MC14 & GTCGCGCTCACACTCGATAA & mALT, $+271 /+291$ \\
\hline MC15 & TTCTGAGCTGGAGGCAGTAGGC & $\mathrm{HNF} 4 \alpha,+1289 /+1310$ \\
\hline MC16 & GCCGATTCATAATGGTCAAATC & HNF $4 \alpha,+1238 /+1259$ \\
\hline MC17 & CGTCCACCGCAAATGCTTC & $\beta$-actin, $+1107-+1125$ \\
\hline MC18 & GTTGTTGGGCGTTGGTTGG & $\beta$-actin, $+1170 /+1152$ \\
\hline MC19 & AACCACATGTACTCCTGCAGGTT & $\begin{array}{l}\mathrm{HNF} 4 \alpha \text { rat, }+282 /+304 \text { in } \\
\text { S. aurata }\end{array}$ \\
\hline MC20 & GCTTGGCTGTTTGGGCACTG & $\begin{array}{l}\text { HNF4 } \alpha \text { zebrafish, } \\
+1342 /+1361 \text { in } S . \text { aurata }\end{array}$ \\
\hline $\mathrm{MC} 21$ & GAAGCTTGCCGCCATGGACATGGCAGACTACAGCG & HNF $4 \alpha,+39 /+60$ \\
\hline MC22 & GGGATCCTTAGATGGCCTCTTGCTTTGTAATAG & $\mathrm{HNF} 4 \alpha,+1378 /+1403$ \\
\hline HNF4 $\alpha$-cons & GGAGCTGGTCAAAGGTCACCTGCAGCT & $\begin{array}{l}\text { ApoCIII rat (Hertz et al, } \\
1995)\end{array}$ \\
\hline mALT-66/-37 & GCTCTGAGCGGTCCAAAGGTCTGAGTCAGC & mALT, $-66 /-37$ \\
\hline $\begin{array}{l}\text { mALT-66/-37 } \\
\text { mutHNF4 } \alpha\end{array}$ & GCTCTGAGCGGTCCACACGTCTGAGTCAGC & mALT, $-66 /-37$ \\
\hline IMAL 28 & GAGTTCCACTCCTGTCGAGT & $\mathrm{mALT},+1 /+21$ \\
\hline IMAL 29 & СTTCTCTTTGGGGAGCCCGC & mALT, $+296 /+277$ \\
\hline
\end{tabular}




\begin{tabular}{lll} 
BA0199 & GACAACGGATCCGGTATGTGC & $\beta$-actin, $+31 /+51$ \\
BA0299 & GACCTGTCCGTCGGGCAGCTC & $\beta$-actin, $+741 /+721$ \\
MC23 & CTGGACCTCCTGGTGCTGATTCTGTCTC & HNF4 $\alpha,+439 /+412$ \\
MC24 & CTGCACGGCTTCTTTCTTCATGCC & HNF4 $\alpha,+404 /+381$ \\
MC25 & CAGCCGGTGAGGAGTCTGTGCCCAGTG & HNF4 $\alpha,+141 /+115$ \\
MC26 & GGGTCCAGAGCCTCGCTGTAGTCTGCC & HNF4 $\alpha,+73 /+47$ \\
MC27 & GTGTCCAACAACATGCCAACGCCG & HNF4 $\alpha,+1218 /+1241$ \\
MC28 & CCCGATCCCGTCTCCGCCTACTGCC & HNF4 $\alpha,+1274 /+1298$ \\
MC29 & GGTAGTTGAGAATTTGTTTGTCCAAAGCG & HNF4 $\alpha,+1 /+29$ \\
MC30 & TTATAAAAATAGACCTTGAGATTTATTAATTCATC & HNF4 $\alpha,+2320 /+2286$ \\
IMAL 24 & GAGGATCCATTTAAGAATACTGCTGAGTGAAC & mALT,$+1766 /+1742$ \\
YM1 & GGAAGCTTAAAAATGTCTGCTACAAGGATGCAGCT & mALT, $+95 /+125$ \\
& GCTG & \\
JDRT18S & TTACGCCCATGTTGTCCTGAG & Ribosomal $18 \mathrm{~s}$ \\
JDRT18AS & AGGATTCTGCATGATGGTCACC & Ribosomal 18s \\
JDRTm1S & CCAGGGTCCGCTCACTGAT & mALT, $+195 /+214$ \\
JDRTm1AS & GTCGCGCTCACACTCGATAA & mALT,$+271 /+291$ \\
\hline
\end{tabular}

Primers used in the present study. The following primers contain restriction sites indicated in bold and underlined: MC05, MC21 and YM1 HindIII; MC022 and IMAL24 BamHI; MC06, MC07 and MC08 MluI; MC09 PmacI; and MC10 Esp3I. For double-stranded oligonucleotides HNF4acons, mALT-66/-37 and mALT-66/-37 mutHNF4 $\alpha$, used in gel shift experiments, only the forward oligonucleotide is shown. 


\section{Table 2.}

Kinetic parameters of $S$. aurata mALT

Forward reaction

\begin{tabular}{ll}
\hline$K_{\mathrm{m}}$ Ala $(\mathrm{mM})$ & $2.22 \pm 0.221$ \\
$K_{\mathrm{m}}$ 2-Oxo $(\mathrm{mM})$ & $0.21 \pm 0.036$ \\
$V \max (\mu \mathrm{mol} /(\mathrm{min} / \mathrm{g}))$ & $402.54 \pm 67.56$ \\
$V \max / K_{\mathrm{m}}$ Ala & 0.182 \\
$V \max / K_{\mathrm{m}}$--Oxo & 1.890 \\
\hline Reverse reaction & \\
\hline$K_{\mathrm{m}} \mathrm{Glu}(\mathrm{mM})$ & $11.30 \pm 2.651$ \\
$K_{\mathrm{m}} \mathrm{Pyr}(\mathrm{mM})$ & $0.32 \pm 0.169$ \\
$V \max (\mu \mathrm{mol} /(\min / \mathrm{g}))$ & $533.76 \pm 21.5$ \\
$V \max / K_{\mathrm{m}} \mathrm{Glu}$ & 0.047 \\
$V \max / K_{\mathrm{m}} \mathrm{Pyr}$ & 1.678
\end{tabular}

Protein extracts from $S$. cerevisiae strain YDR089c expressing S. aurata mALT were assayed for ALT activity at various substrate and cosubstrate concentrations to calculate $K_{\mathrm{m}}$ and $V_{\max }$ values. The results presented are the mean \pm standard deviation of experiments performed at least with two different enzyme preparations. 


\section{Figure 1}

A

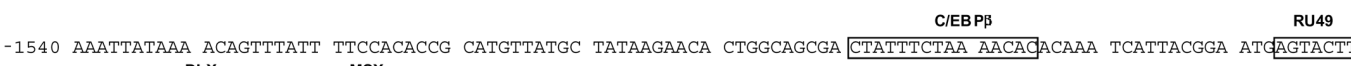
DLX
- 1440 TSX
GTGGAATGA TAATTGCAAT TGTTTTAATT GCACTGATTG TTTCAAGAAG TCACACTTTT ACTTTACTGC AAATCCCAGT TACATCCCAG TATGTAGTTT -1340 CTAATCACAG ATGCTGTTCT CCTCATTATC CTTTAGTACG GGGGGGGCAA AACTTTTCAC TTGAAAGGGC CCAAACTTAG AAAATACTGG TTGATAGGGA

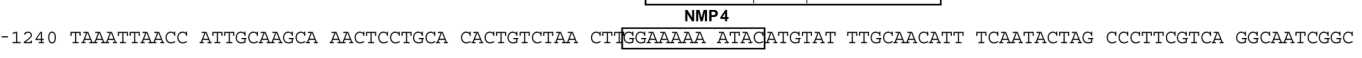

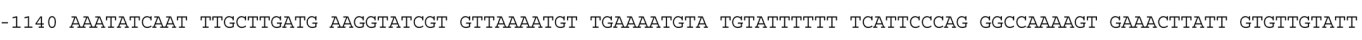

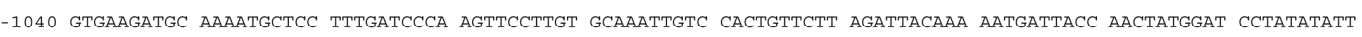

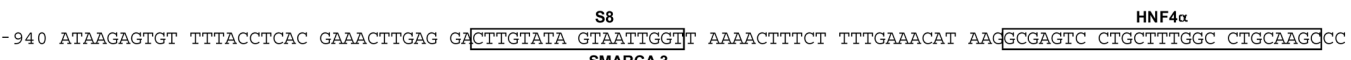

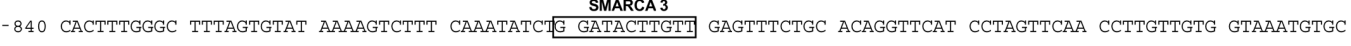

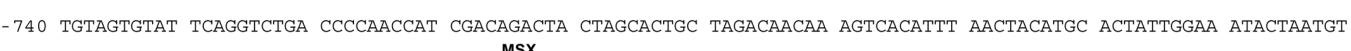

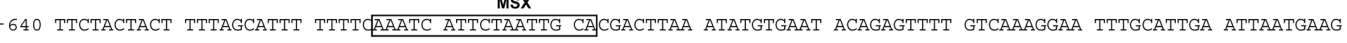

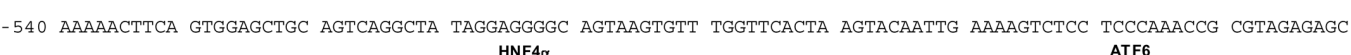
- 440 AGACAGCGGT GGGTGAGCTG AGGTGAGCTC GGGACAAAAG TTGGGAGCAG CTCCCAGATT TGCTAGTTAG AATCICTCTG AGCCACGTCA GTCGAवCCAA - 340 AGCTGCCTCG GCTCGGTAAC CGGAGAACCG AACCCGAGAT ACGGCCTCAC GGTGCGTAGG GTAACGGGG ACAGGGGGG TGGATAACGg tCGAGCTGAA -240 GCCACACAAA GGGGGAGGGA TAGTTGCAGC GTTGCCATGT GTGCAAGGAA CAGGCCCCCC AAAAAACTTC CCAGAGTGTA AATTCACGTG CGTGTGTGGA - 140 TGCGAGCAGG GTCTGAAGAg ACGCTCTGAG AATTTGTCCC ACTTTTTATT CGGAGCCCCG TTAGCTCTTC CCCCGCTCTG AGCGGTCCAA AGGTCTGAGT

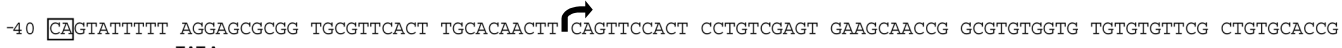
+60 CGGA $\frac{\text { TATA }}{\text { GGCTTT AAAAGTCACC CAACTCGCCG TGttaaacat getggctaca aggatgcag }}$

B

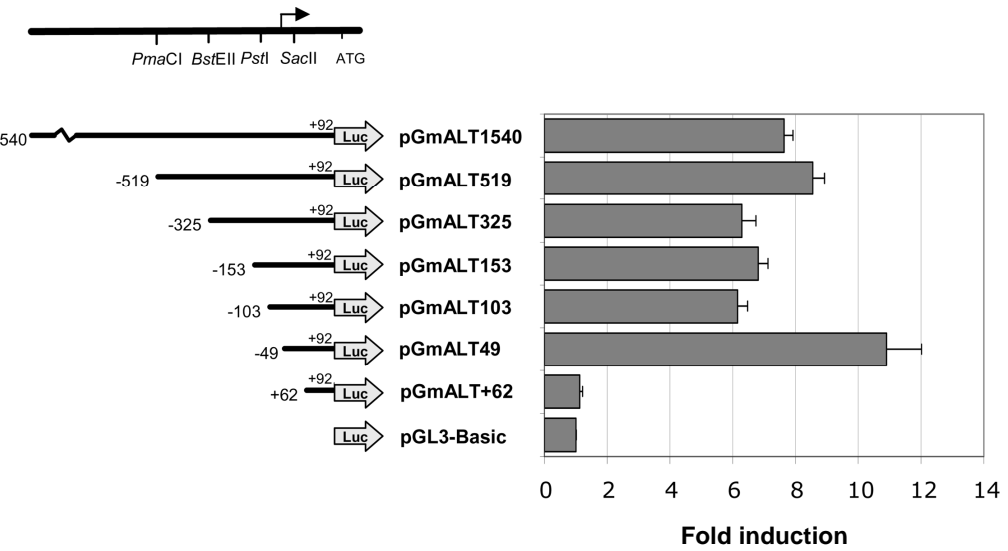


Figure 2

A
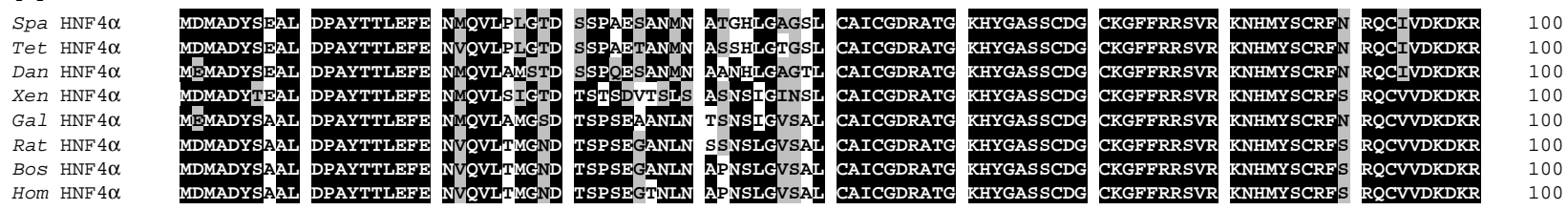

Spa HNF $4 \alpha$
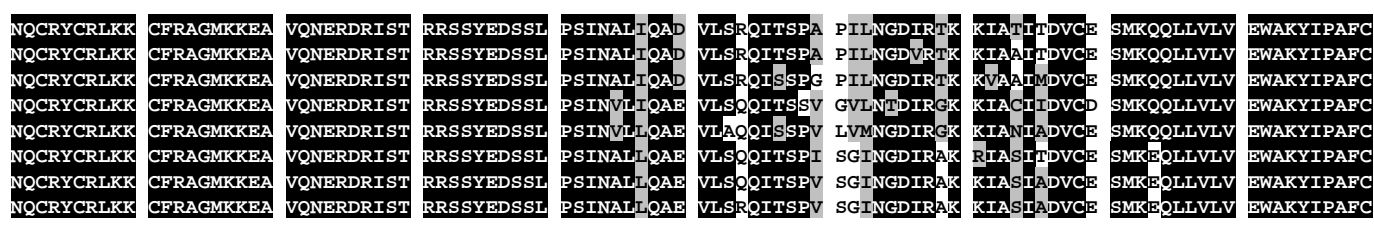

200
200
200
200
200
200
200
200

Spa HNF $4 \alpha$

Tet HNF $4 \alpha$

Dan HNF $4 \alpha$

Xen $\operatorname{HNF} 4 \alpha$

Rat HNF $4 \alpha$

Rat HNF $4 \alpha$
Bos $\mathrm{HNF} 4 \alpha$
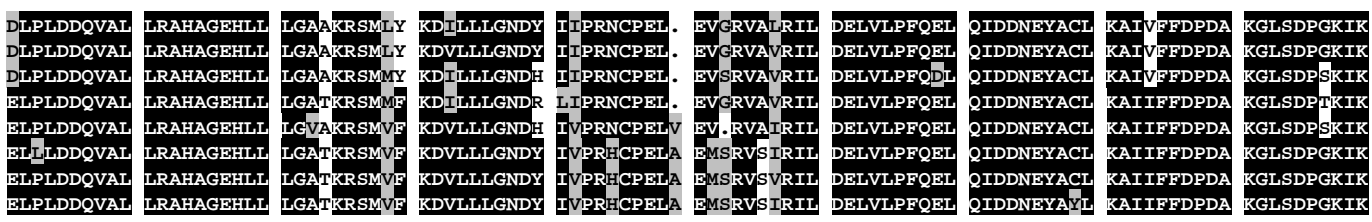

299

Spa HNF $4 \alpha$

Tet HNF $4 \alpha$

Dan HNF $4 \alpha$

Xen $\operatorname{HNF} 4 \alpha$

Gal HNF $4 \alpha$

BOS HNF $4 \alpha$

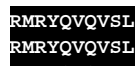

WDYINDRQYD
EDY INDRQYD
EDY INDRQYD

$\begin{array}{lll}\text { SRGRFGELLI LLPTLQSITW } & \text { QMIEQIQFVK } \\ \text { SRGRFGELLI LLPTLQSITW } & \text { QMIEQIQFVK } \\ \text { SRGRFGELLI LLPTLOSITW OMIEOIOFVK }\end{array}$

RMRYQVQVSI

RMRYQVQVS

RLISQVevsI

EDYINDRQYD

SRGRFGELLL LIPTLOSTTW OMIEOIOFV

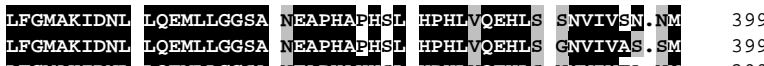

LOEMLLGGS

OIDDNEYA

KAIIFFDPDA

GLSDPGKIK

$\begin{array}{llll}\text { LFGMAKIDNL LQEMLLGGSA NIAPHAHHSL HPHLVQEHLS NNVIVTA.NM } & 399 \\ \text { LFGMAKIDNL LQEMLLGGSA NEASHTHHHL HPHLVDDHLA TNVIVANNTI } & 400\end{array}$

RLRSQVQVSL EDYINDROYD

OMIEOIOFVK LFGMAKIDN

SRGRFGELLL LLPTLQSITW QMIEQIQFI

LFGMAKIDNL

QEMLLGGS SETPHAHHPL HPHLIOENLG TNVIVAN. TM 399

Hom $\operatorname{HNF} 4 \alpha$

Spa $\operatorname{HNF} 4 \alpha$

Tet $\operatorname{HNF} 4 \alpha$

Dan $\operatorname{HNF} 4 \alpha$

Xen $\operatorname{HNF} 4 \alpha$

Gal $\operatorname{HNF} 4 \alpha$

Rat $\operatorname{HNF} 4 \alpha$

BOS HNF $4 \alpha$
Hom $\operatorname{HNF} 4 \alpha$

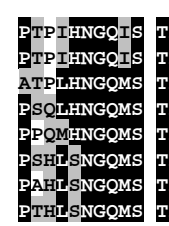

EDYINDROY

SRGRFGELLI LLPTLQSITW OMIEQIQFIK
SRGRFGELLI LLPTLOSITW OMIEOIOEIK

LFGMAKIDNL LOEMLLGGSS SDAPHAHHPL HPHLMOEHMG TNVIVAN. MU
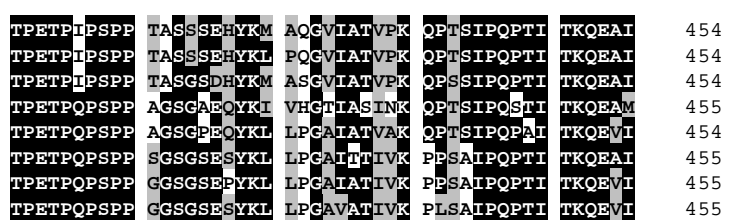

B

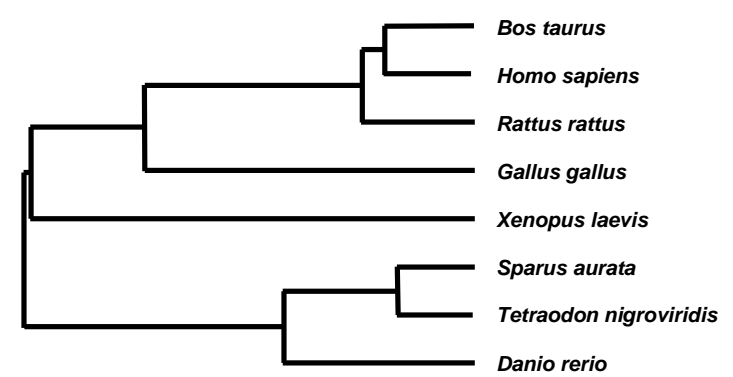


Figure 3

A

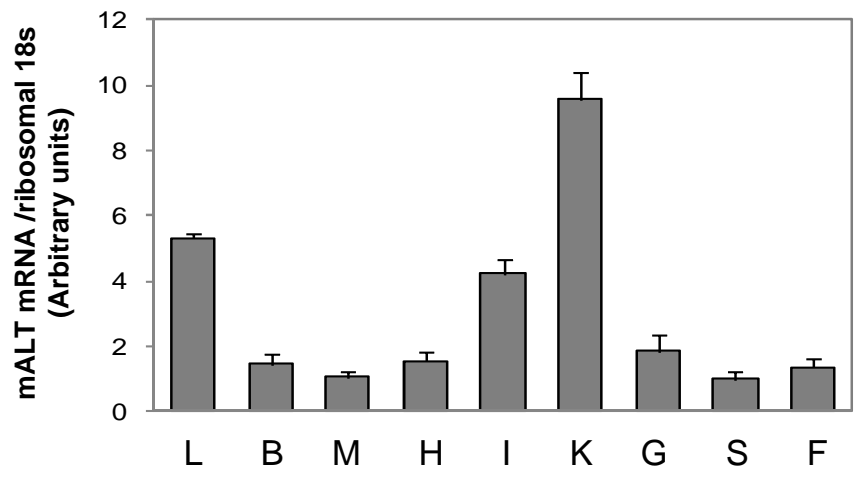

B

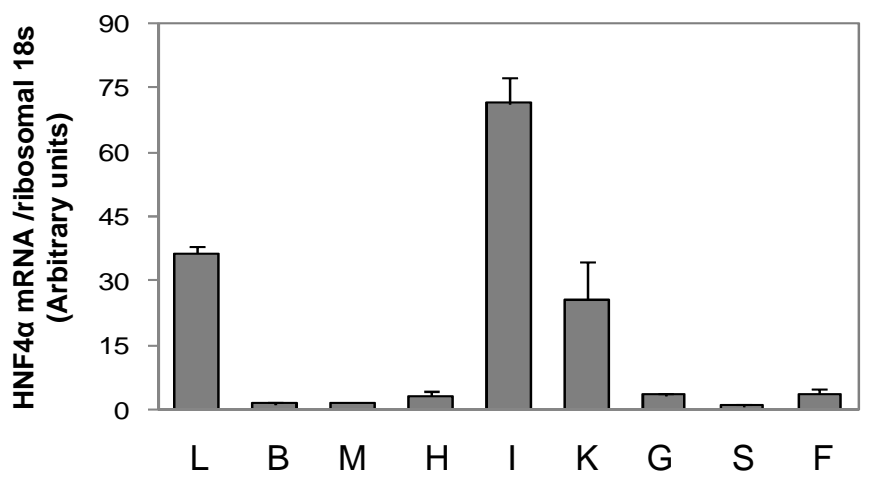


Figure 4

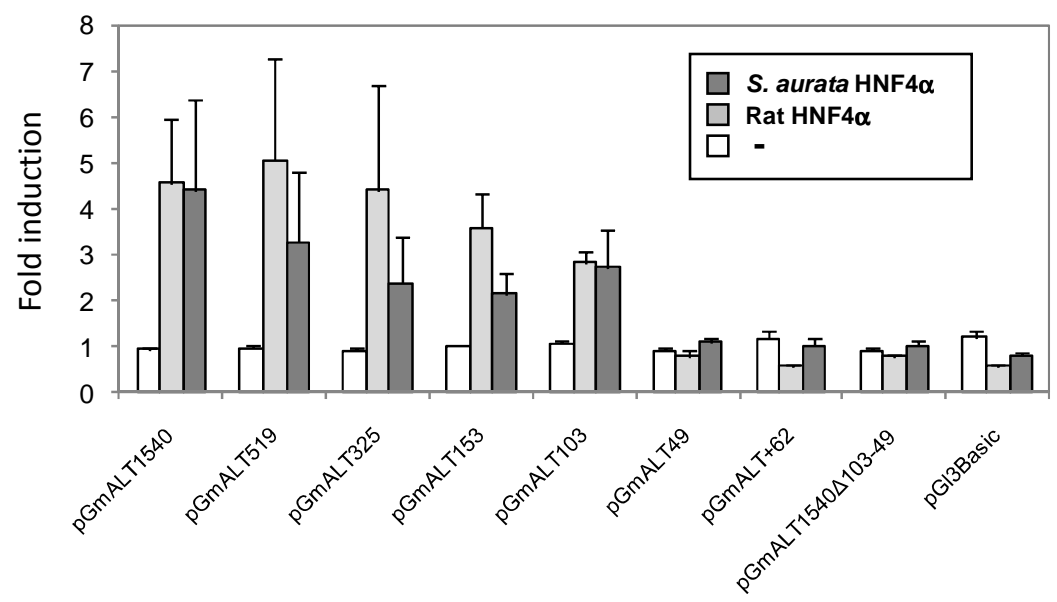


Figure 5

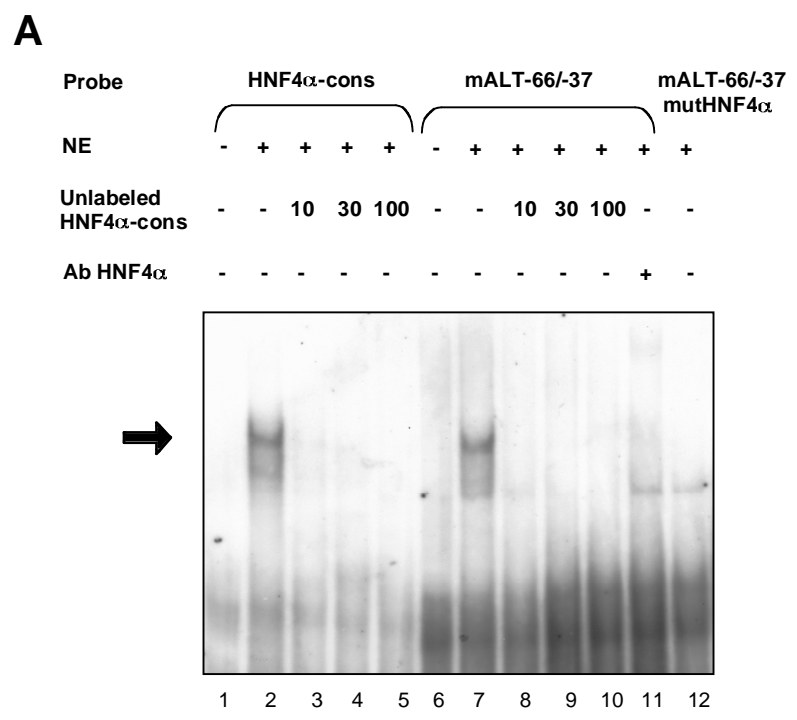

B

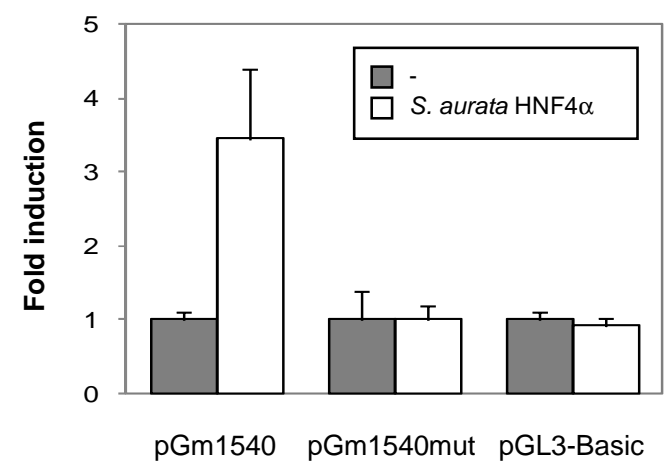


Figure 6
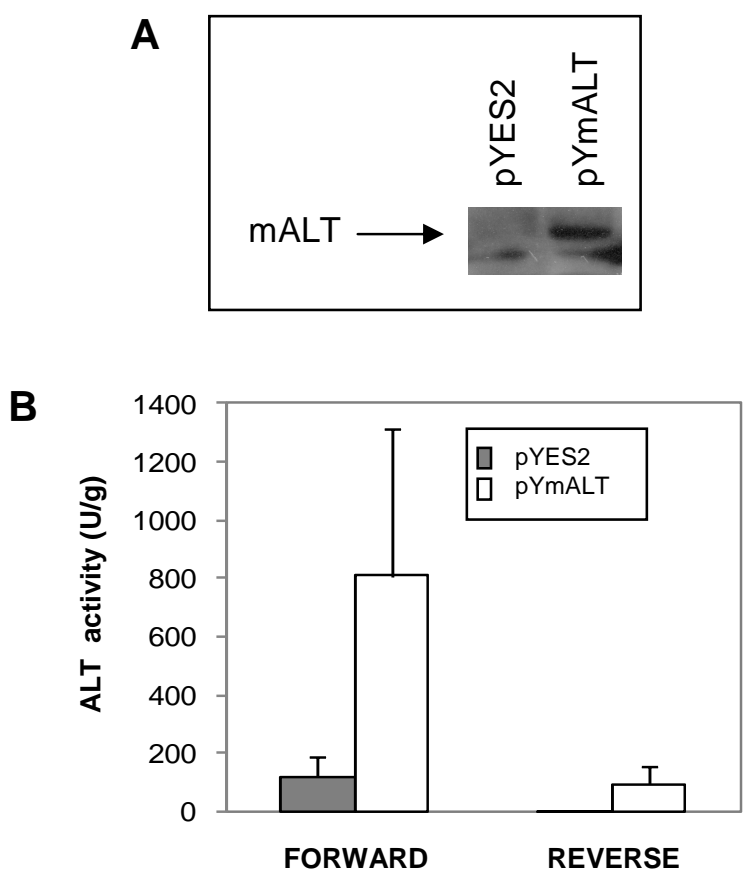
Figure 7

A

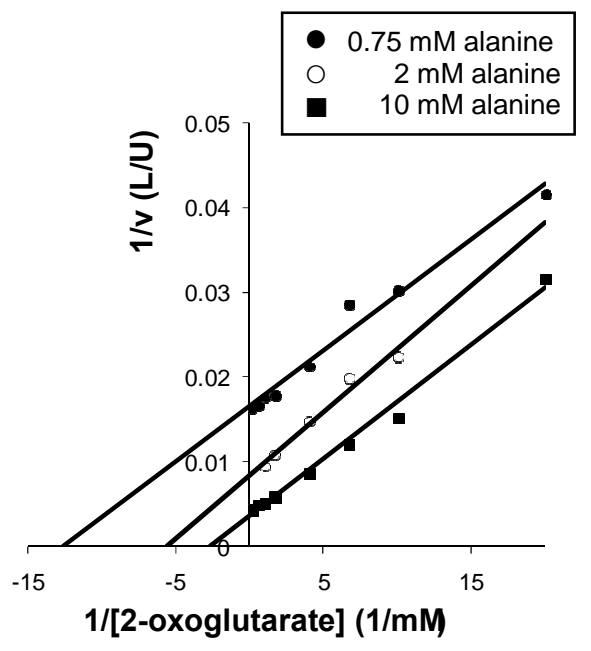

C

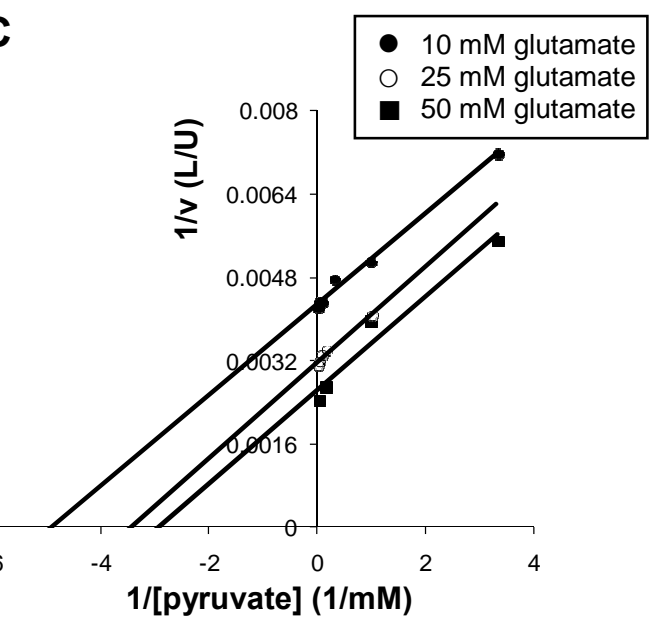

B

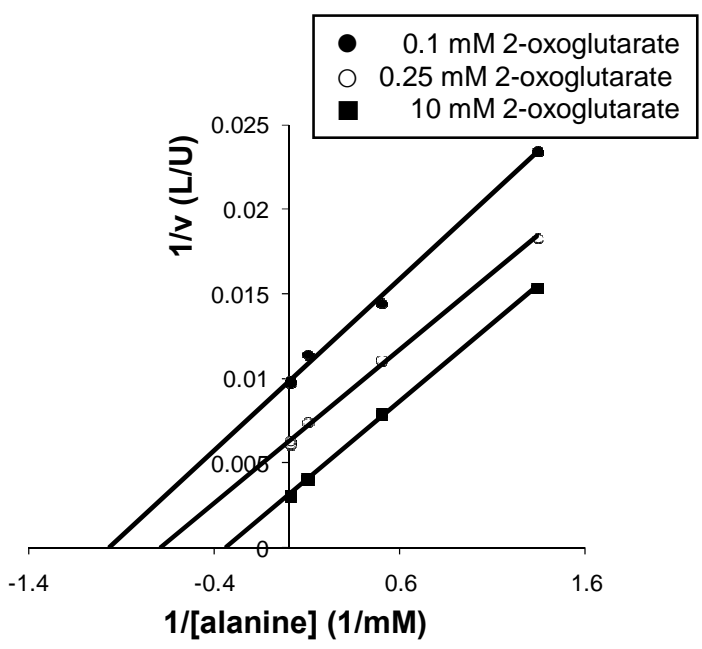

D

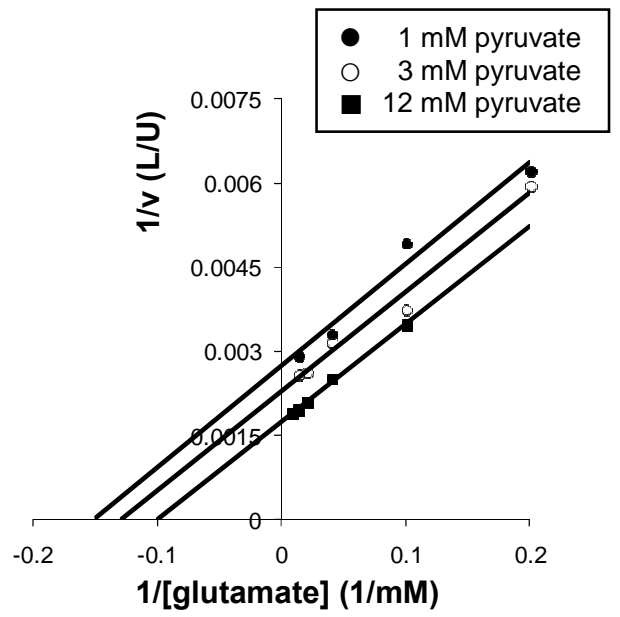


Figure 8

A

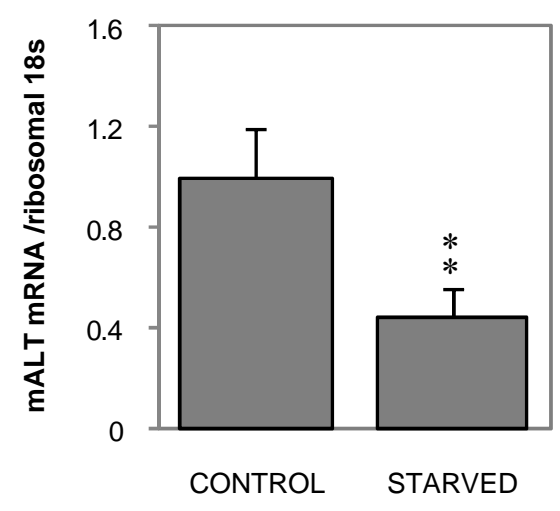

C

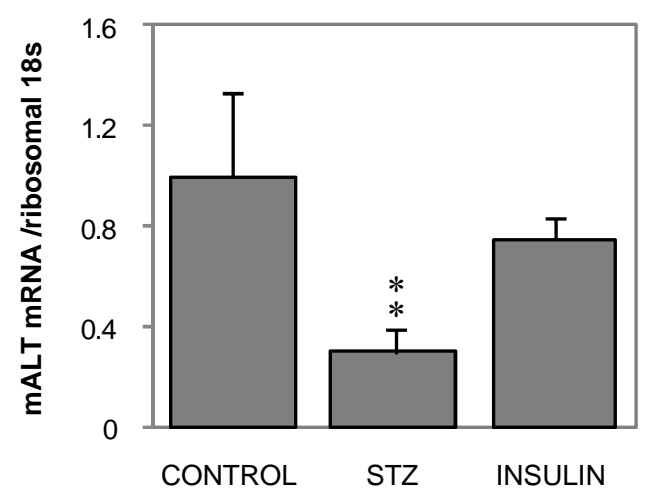

B

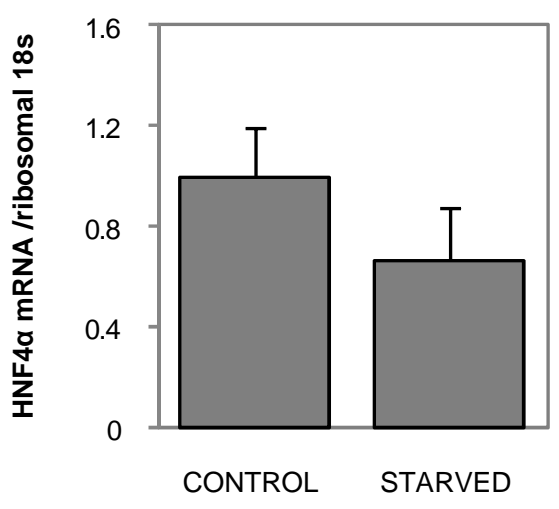

D

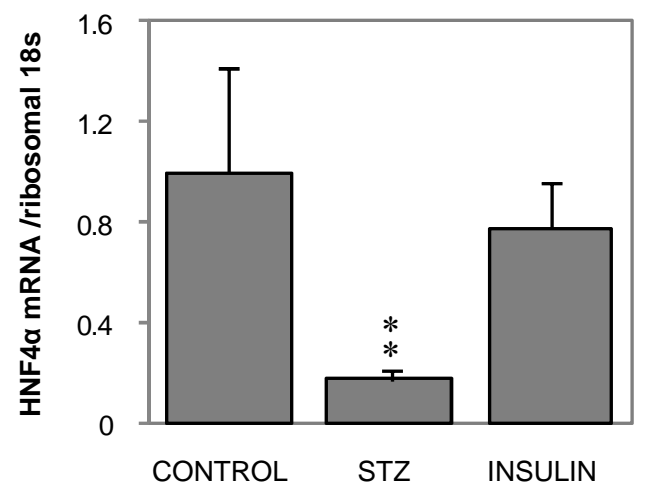

